\title{
Using Maximum Entropy Production to Describe Microbial Biogeochemistry Over Time and Space in a Meromictic Pond
}

\author{
Joseph J. Vallino ${ }^{1 *}$ and Julie A. Huber ${ }^{2}$ \\ ${ }^{1}$ Marine Biological Laboratory, Ecosystems Center, Woods Hole, MA, United States, ${ }^{2}$ Woods Hole Oceanographic \\ Institution, Marine Chemistry and Geochemistry, Woods Hole, MA, United States
}

Determining how microbial communities organize and function at the ecosystem level is essential to understanding and predicting how they will respond to environmental change. Mathematical models can be used to describe these communities, but properly representing all the biological interactions in extremely diverse natural microbial ecosystems in a mathematical model is challenging. We examine a complementary approach based on the maximum entropy production (MEP) principle, which proposes that systems with many degrees of freedom will likely organize to maximize the rate of free

OPEN ACCESS

Edited by:

Anke Marianne Herrmann,

Swedish University of Agricultural

Sciences, Sweden

Reviewed by:

Mustafa Yucel,

Middle East Technical University,

Turkey

John Senko,

University of Akron, United States

*Correspondence: Joseph J. Vallino jvallino@mbl.edu

Specialty section: This article was submitted to Microbiological Chemistry and Geomicrobiology,

a section of the journal

Frontiers in Environmental Science

Received: 07 February 2018 Accepted: 23 August 2018

Published: 01 October 2018

Citation:

Vallino JJ and Huber JA (2018) Using Maximum Entropy Production to

Describe Microbial Biogeochemistry Over Time and Space in a Meromictic Pond. Front. Environ. Sci. 6:100. doi: 10.3389/fenvs.2018.00100 energy dissipation. In this study, we develop an MEP model to describe biogeochemistry observed in Siders Pond, a phosphate limited meromictic system located in Falmouth, MA that exhibits steep chemical gradients due to density-driven stratification that supports anaerobic photosynthesis as well as microbial communities that catalyze redox cycles involving $\mathrm{O}, \mathrm{N}, \mathrm{S}, \mathrm{Fe}$, and $\mathrm{Mn}$. The MEP model uses a metabolic network to represent microbial redox reactions, where biomass allocation and reaction rates are determined by solving an optimization problem that maximizes entropy production over time, and a 1D vertical profile constrained by an advection-dispersion-reaction model. We introduce a new approach for modeling phototrophy and explicitly represent oxygenic photoautotrophs, photoheterotrophs and anoxygenic photoautotrophs. The metabolic network also includes reactions for aerobic organoheterotrophic bacteria, sulfate reducing bacteria, sulfide oxidizing bacteria and aerobic and anaerobic grazers. Model results were compared to observations of biogeochemical constituents collected over a $24 \mathrm{~h}$ period at 8 depths at a single $15 \mathrm{~m}$ deep station in Siders Pond. Maximizing entropy production over long ( 3 day) intervals produced results more similar to field observations than short ( 0.25 day) interval optimizations, which support the importance of temporal strategies for maximizing entropy production over time. Furthermore, we found that entropy production must be maximized locally instead of globally where energy potentials are degraded quickly by abiotic processes, such as light absorption by water. This combination of field observations and modeling results indicate that natural microbial systems can be modeled by using the maximum entropy production principle applied over time and space using many fewer parameters than conventional models.

Keywords: maximum entropy production, microbial biogeochemistry, metabolic networks, phototrophy, community function, meromictic 


\section{INTRODUCTION}

Mass and energy flow associated with the growth and predation of bacteria, archaea and eukaryotes in microbial food webs, coupled with abiotic reactions and transport processes, define biogeochemical cycles that occur in ecosystems ranging in size from less than a liter (Marino et al., 2016) to the entire planet. Because organisms are ultimately responsible for most observed biogeochemical transformations, it is customary and natural to focus on the bioenergetics of growth and predation of organisms that constitute food webs in order to understand and predict biogeochemical transformations. This organismal focus has a long history and has advanced our understanding and prediction of ecosystem dynamics and the mass and energy flow through them (Riley, 1946; Fasham et al., 1990; Le Quere et al., 2005; Friedrichs et al., 2007; Schartau et al., 2017). While focusing on the growth, predator-prey and cooperative interactions of organisms will continue to contribute to our understanding of ecosystem bioenergetics, there are some challenges that limit this approach for microbial systems that form the basis of biogeochemical cycles. Microbial communities are diverse, complex and abundant, consisting, for example, of approximately $10^{9}$ microorganisms per liter of seawater, with estimates that Earth hosts close to 1 trillion microbial species (Sogin et al., 2006; Locey and Lennon, 2016). With the advent of metagenomics, next generation sequencing and bioinformatics, the challenging task of deciphering and annotating the metabolic capabilities and activities of bacteria and other microorganisms has begun, but determining how information in genomes contributes to competition and cooperation is still in its infancy (Hallam and McCutcheon, 2015; Pasternak et al., 2015; Worden et al., 2015). Even more challenging is understanding and predicting community composition dynamics and succession as environmental conditions change, both from exogenous and endogenous drivers (Konopka et al., 2015). While considerable progress is being made in developing predictive models of biogeochemistry based on organisms and the genes they carry (Reed et al., 2014; Coles et al., 2017), the ability for this approach to encompass the complex biogeochemistry of the ecosystem will likely take many decades to compile and decipher. We believe the reductionist approach is essential, but there is also a complementary approach to understanding microbial biogeochemistry that is less studied and uses a more thermodynamic, or whole systems, approach.

Understanding how ecosystems function at the systems level has a long tradition in theoretical ecology (Chapman et al., 2016; Vallino and Algar, 2016), with the underlying premise that ecosystems organize so as to maximize an objective function, such as maximizing power proposed by Lotka (1922) nearly 100 years ago. The advantage of the systems approach is that optimization can be used to determine how an ecosystem will organize and function without the knowledge of which organisms are present and how their population changes over time. Understanding and modeling of ecosystems can focus on function rather than on organisms, and there is growing support that stable function arises from dynamic communities (Fernandez et al., 1999; Fernandez-Gonzalez et al., 2016; Louca and Doebeli, 2016; Needham and Fuhrman, 2016; Coles et al.,
2017). Here, we build upon the assumption that microbial systems organize to use all available energy sources. To use the correct thermodynamic term, living organisms use Gibbs free energy, since energy is conserved, but Gibbs free energy (aka usable energy) is not. The destruction of Gibbs free energy or energy potentials results in entropy production, so the net action of life produces entropy, because contrary to conventional wisdom, living organisms are not low entropy structures (Morrison, 1964; Blumenfeld, 1981). This allows us to employ the maximum entropy production (MEP) principle, which proposes that systems with sufficient degrees of freedom will likely organize to maximize the dissipation of Gibbs free energy (Dewar, 2003; Lorenz, 2003; Martyushev and Seleznev, 2006). In an ecological context, if food (which includes organisms themselves) is available but not being consumed, then organisms will eventually adapt, invade or evolve to utilize it if biologically possible. This simple concept forms the basis of this manuscript. The MEP principle has been applied to both abiotic and biotic processes (Kleidon and Lorenz, 2005; Kleidon et al., 2010; Dewar et al., 2014b), and we have used MEP to model periodically forced methanotrophic microbial communities (Vallino et al., 2014) and investigate metabolic switching in nitrate reducing environments (Algar and Vallino, 2014). While MEP is consistent with Darwinian evolution, and likely guides its trajectory (Goldenfeld and Woese, 2011; Skene, 2015, 2017; Judson, 2017), it has yet to gain general acceptance in theoretical or experimental ecological communities largely because of an insufficient number of case studies and uncertainty in how to apply it.

In this study we develop an MEP-based model to predict microbial biogeochemistry in a meromictic pond located in Falmouth, MA (Siders Pond) that includes metabolic processes for phytoplankton, green sulfur bacteria, aerobic organoheterotrophic bacteria, sulfate reducing bacteria, sulfide oxidizing bacteria, photoheterotrophs and aerobic and anaerobic predators (Figure 1). However, the model's objective function is to dissipate energy potentials, not grow organisms. While previous MEP models have been developed for chemolithoautotrophs, chemolithoheterotrophs, and chemoorganoheterotrophs, this study expands the metabolic reaction repertoire to include photoautotrophs and photoheterotrophs. The approach is also extended to include an explicit spatial dimension, and we compare model output to observations in Siders Pond collected over a $24 \mathrm{~h}$ sampling period from eight depths. MEP solutions using two different optimization timescales ( 0.25 day vs. 3.0 days) are contrasted and compared to observations, and we discuss the problem of local vs. global MEP optimization for energy potentials that are quickly dissipated abiotically, such as light. Our results suggest that microbial systems in nature can be described by the maximum entropy production conjecture applied over time and space.

\section{RATIONALE}

Our interest in investigating the applicability of MEP theory for describing microbial communities has, in addition to the basic science question, an applied objective. Standard models used to describe microbial biogeochemistry contain a large number of 
poorly constrained parameters, such as maximum growth rates, substrate affinity constants, growth efficiencies, prey preferences, substrate inhibition constant, and others. Consequently, data are required to determine parameter values, but since there is almost always more parameters than constraining observations, it is not difficult to obtain good agreement between model output and observations. Consequently, a good model fit does not equate to an understanding of the underlying mechanisms in a system. As a consequence, such models usually do poorly when extrapolated to different systems (Vallino, 2000; Ward et al., 2010). Parameters must be recalibrated for new conditions, but this defeats the purpose of developing a model, as we are often interested in using a model to predict how a system will respond to new conditions that have yet to occur. If the MEP principle fundamentally describes microbial communities, then models based on MEP should exhibit better extrapolation performance, since MEP would still be an appropriate objective function even under new conditions.

A challenging and unresolved aspect of MEP principle involves the temporal and spatial scales over which it applies (Dewar et al., 2014a). MEP theory has been developed for nonequilibrium steady-state systems where time is removed from the derivation, but natural microbial communities are dynamic and often far from steady state. For non-steady-state systems, we have proposed the following distinctions (Vallino, 2010). Abiotic processes, such as fire or a rock rolling down a hill, maximize instantaneous entropy production. That is, they follow a steepest descent trajectory down a potential energy surface in progress toward equilibrium, but this pathway can lead to metastable states that prevent further progress and entropy production. For instance, the flame gets extinguished or the rock gets stuck in a ditch partway down the hill. Biological systems, however, have evolved temporal strategies, such as circadian rhythms, that allow the system to take an alternate pathway that is not as steep, but it avoids metastable traps and enables further progress down the free energy surface. While instantaneous entropy production is lower in biological systems, when averaged over time, the integrated entropy production is greater than abiotic processes. Since MEP theory proposes that system configurations that produce more entropy are more likely to prevail (Lorenz, 2003), the higher average entropy production by biological systems allow them to persist over abiotic processes, at least in some situations. Similarly, when considering a spatial domain, entropy production can either be maximized locally at each point in the domain, or entropy production at each point can be adjusted so that entropy production is maximized globally over the entire domain. A simple numerical study indicated that when a system organizes over space, entropy produced by global optimization can exceed that from local optimization, but this requires spatial coordination by the community, while abiotic systems are likely to only maximize entropy production locally (Vallino, 2011). This paper will explore how changes in time and space scales over which entropy is maximized alters model predictions of microbial biogeochemistry. To provide some grounding in reality, model predictions are compared to biogeochemical observations. The purpose of this manuscript is to demonstrate one particular implementation of how MEP can

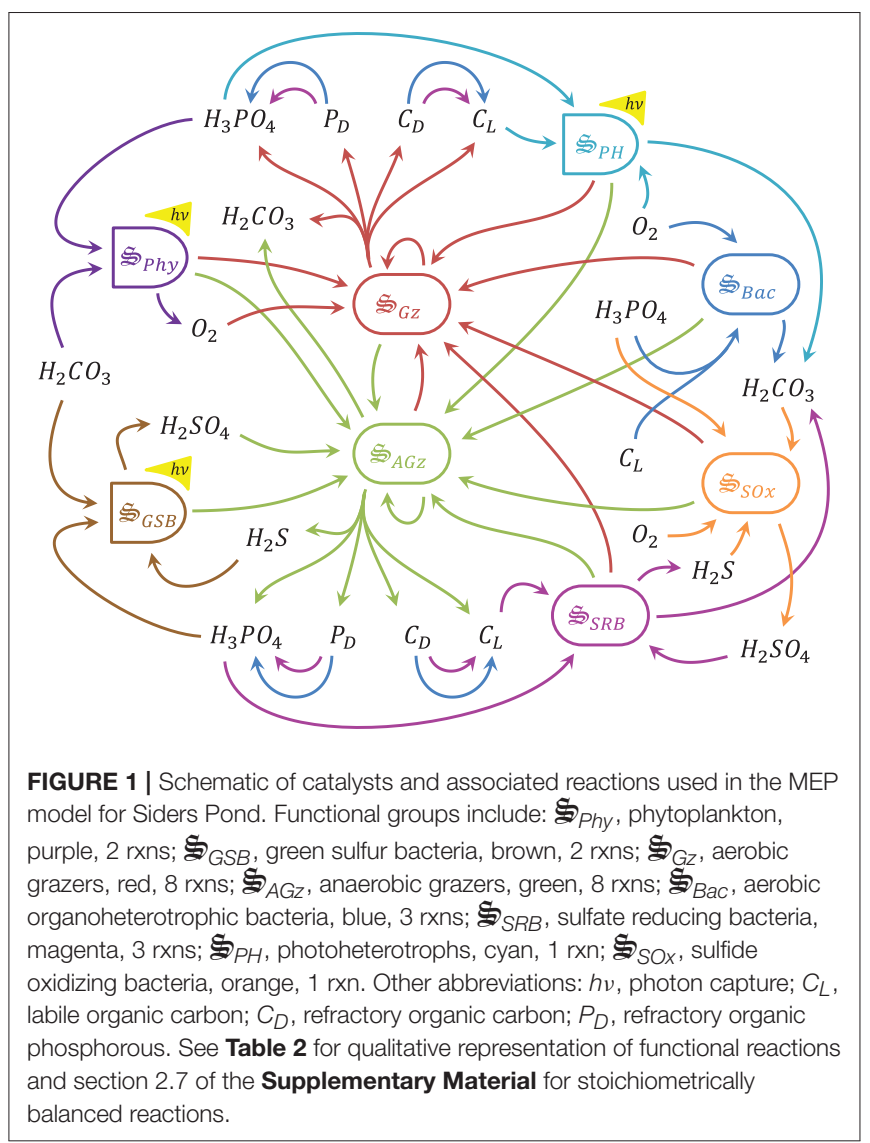

be used to describe microbial biogeochemistry in natural systems that goes beyond a simple conceptual model, but ours is certainly not the only approach.

\section{METHODS}

This section describes Siders Pond sample collection procedures and sample analyses followed by the development of the MEP model and associated 1D transport model for Siders Pond.

\section{Siders Pond \\ Site Description}

Siders Pond is a small coastal meromictic kettle hole (volume: $10^{6} \mathrm{~m}^{3}$; area: $13.4 \mathrm{ha}$; maximum depth: $15 \mathrm{~m}$ ) that receives approximately $1 \times 10^{6} \mathrm{~m}^{3}$ of fresh and $0.15 \times 10^{6} \mathrm{~m}^{3}$ of saltwater each year (Caraco, 1986). The latter input occurs via a small creek that connects the pond to Vineyard Sound approximately $550 \mathrm{~m}$ to the south. Tritium-helium water dating confirmed vertical mixing across two observed chemoclines, but permanent stratification is maintained because the saltwater inputs enter the pond at depth, mix upward and become entrained with freshwater before exiting the pond (Caraco, 1986). Caraco (1986) also characterized $\mathrm{N}$ and $\mathrm{P}$ loading to the pond $\left(50 \mathrm{~g} \mathrm{~N} \mathrm{~m}^{2} \mathrm{y}^{-1}\right.$ and $1.3 \mathrm{~g} \mathrm{P} \mathrm{m}^{-2} \mathrm{y}^{-1}$, respectively), and an $\mathrm{N}+\mathrm{P}$ enrichment study (Caraco et al., 1987) showed phytoplankton to be P limited, especially in the low salinity surface waters. Previous studies show 
Siders Pond is eutrophic averaging $16 \mathrm{mg} \mathrm{m}^{-3}$ chlorophyll a (Chl a) in surface waters (but can exceed $100 \mathrm{mg} \mathrm{m}^{-3}$ at times) and an annual primary productivity of $315 \mathrm{~g} \mathrm{C} \mathrm{m}^{-2}$ (Caraco, 1986; Caraco and Puccoon, 1986). In anoxic bottom waters, bacterial $\mathrm{Chl} \mathrm{c}$, d and e associated with photosynthetic green sulfur bacteria averages $20 \mathrm{mg} \mathrm{m}^{-3}$ (purple sulfur bacteria were not found in high concentration), but BChl cde was also observed to reach high concentrations at times $\left(>75 \mathrm{mg} \mathrm{m}^{-3}\right)$. Even though green sulfur bacteria could attain high concentrations, their productivity was only $6 \%$ of the oxygenic photoautotroph (cyanobacteria + algae) production (Caraco, 1986). Siders Pond was chosen for this study because extensive redox cycling occurs over a $15 \mathrm{~m}$ deep water column, which greatly facilitates sampling due to the large water volumes that can be readily collected without perturbing the system.

\section{Sampling and Measurements}

Samples were collected from Siders Pond, Falmouth, MA over a $24 \mathrm{~h}$ period starting at $6: 45$ on Jun 25 th and ending at 7:37 on Jun 26th, 2015 from a single station located within the deepest basin of the pond $\left(41.548212^{\circ} \mathrm{N}, 70.622412^{\circ} \mathrm{W}\right)$. A total of 7 casts were conducted over the $24 \mathrm{hr}$ period, and each cast sampled 8 depths to generate a 2D sampling grid designed for comparison to model outputs (Figure 2). A Hydrolab DS5 water quality sonde (OTT Hydromet, $\mathrm{GmbH}$ ) was connected to a Hydrolab Surveyor 4 handheld display and used to record depth, temperature, salinity, $\mathrm{pH}$, dissolved oxygen (DO), photosynthetic active radiation (PAR), and in situ $\mathrm{Chl}$ a fluorescence. All sensors were calibrated per manufacturer's instructions one day prior to sampling. One end of a $20 \mathrm{~m}$ long section of vinyl tubing with a $1 \mathrm{~cm}$ inside diameter was attached to the water quality sonde, while the other end passed through a Geopump 2 (Geotech, CO) peristaltic pump and then connected to $25 \mathrm{~mm}$ polypropylene, acid washed, in-line Swinnex filter holder (Millipore, MA), which housed a GF/F glass fiber filter (Whatman, GE Healthcare) that had been ashed at $450^{\circ} \mathrm{C}$ for $1 \mathrm{hr}$. At all depths, the vinyl tubing was first flushed for at least $2 \mathrm{~min}$, sample collection vials were washed twice with filtrate and GF/F filters where changed as needed to maintain high flow. This design allowed water samples to be collected at the desired depths and processed on location then preserved on ice or dry ice for later analysis as described below.

Unless otherwise noted, all samples were filtered as described above and stored in $20 \mathrm{~mL}$ acid-washed, highdensity polyethylene scintillation vials (Fisher Scientific). Samples were preserved for later analysis as follows. Inorganic phosphate: $15 \mathrm{~mL}$ samples were amended with $20 \mu \mathrm{L}$ of $5 \mathrm{~N}$ $\mathrm{HCl}$ and placed on dry ice. Dissolved inorganic carbon (DIC) and sulfate: samples were collected in $12 \mathrm{~mL}$ exetainers (Labco, UK) by overfilling bottles from the bottom up, and then capped without bubbles and placed on ice. Hydrogen sulfide: while filling exetainers, $25 \mu \mathrm{L}$ of sample was pipette transferred to $6 \mathrm{~mL}$ of $2 \%$ zinc acetate in a $20 \mathrm{~mL}$ scintillation vial and place on ice. Dissolved organic carbon (DOC): $25 \mathrm{~mL}$ of sample was collected in previously ashed $30 \mathrm{~mL}$ glass vials to which $40 \mu \mathrm{L}$ of $5 \mathrm{~N} \mathrm{HCl}$ was added then stored on ice. Particulate organic carbon (POC):

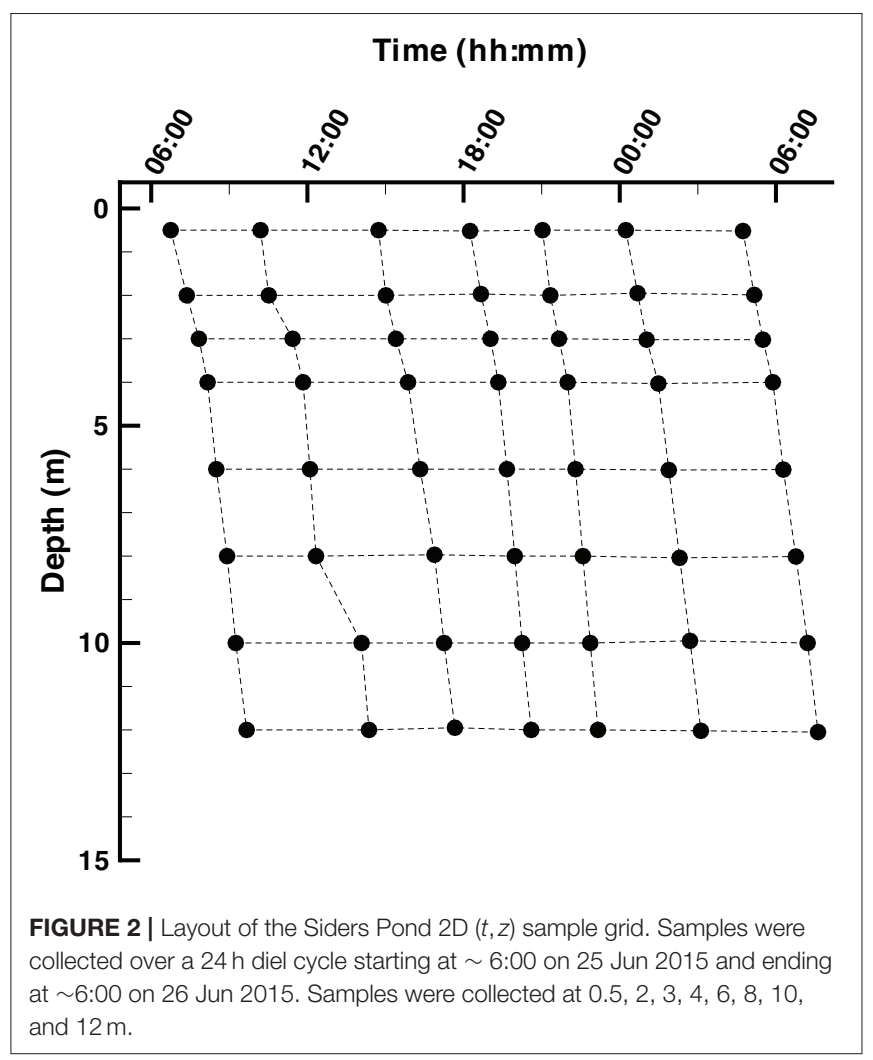

approximately $300 \mathrm{~mL}$ of sample was passed through new, ashed, $25 \mathrm{~mm}$ GF/F filter then stored in a plastic Petri dish on dry ice.

Samples were analyzed at the Ecosystems laboratory, MBL as follows. Phosphate: samples were stored at $-20^{\circ} \mathrm{C}$ then later analyzed following the spectrophotometric method of Murphy and Riley (1962) on a UV-1800 spectrophotometer (Shimadzu, Kyoto, Japan). DIC: samples were immediately run on return to MBL on an Apollo AS-C3 DIC analyzer (Apollo SciTech, DE). Sulfate: samples were sparged with $\mathrm{N}_{2}$ to strip $\mathrm{H}_{2} \mathrm{~S}$ on return to $\mathrm{MBL}$ and stored at $4^{\circ} \mathrm{C}$ then analyzed using ion chromatography on a Dionex DX-120 analyzer (Dionex, Sunnyvale, CA). Hydrogen sulfide: samples were briefly stored at $4^{\circ} \mathrm{C}$ for 5 days then analyzed using the spectrophotometric method of Gilboa-Garber (1971). DOC: samples were stored at $4{ }^{\circ} \mathrm{C}$ then run on a Shimadzu TOC-L high temperature total organic carbon analyzer at $720^{\circ} \mathrm{C}$. POC: samples were stored at $-20^{\circ} \mathrm{C}$ then analyzed on a Thermo Scientific FLASH $2000 \mathrm{CHN}$ analyzer using aspartic acid standards. To facilitate model comparison to observations, Chl a was estimated from modeled output of phototroph biomass concentrations using 12. $\left(\left[\dot{\xi}_{P h y}\right]+\left[\dot{\xi}_{G S B}\right]+\left[\dot{\xi}_{P H}\right]\right) / \theta_{C}:$ Chla, where $\theta_{C: \text { Chla }}$ is the $\mathrm{C}: \mathrm{Chl}$ a ratio, which was set to $50 \mu \mathrm{g} \mathrm{C}(\mu \mathrm{g} \mathrm{Chl} \text { a })^{-1}$ (Sathyendranath et al., 2009).

\section{Model Development}

The equations used to model biogeochemistry in Siders Pond are provided in detail in the Supplementary Material, so the descriptions in this section focus primarily on model concepts 
that form the basis of the modeling approach and extensions to previous studies. The model consists of three main components: (1) a set of biologically catalyzed reactions that constitute the distributed metabolic network of the microbial community, including predators such as protist and viruses; (2) a 1D transport model; (3) an optimization component in which control variables that govern reaction stoichiometry, kinetics and thermodynamics are determined so as to maximize internal entropy production over a specified interval of time and space. We describe briefly below the three model components, but we focus first on the representation of the metabolic network, as this forms the foundation of the approach, and includes the concentrations of 11 chemical constituents and 8 functional groups (Figure 1, Table 1).

\section{Catalysts and Metabolic Reaction Network}

Our approach views a complex microbial community as a collection of catalysts (denoted with the special symbol $\dot{\xi}_{j}$ with the subscript $j$ meaning any of the 8 functional groups in Figure 1) that each have a subset of $n_{r, j}$ functional reactions they catalyze. The catalyst has an elemental composition given by $\mathrm{CH}_{\alpha \mathcal{g}} \mathrm{O}_{\beta} N_{\gamma_{\mathcal{G}}} P_{\delta}$. For this study all catalysts are assigned the same composition as yeast with associated thermodynamic properties (Battley et al., 1997), but this is not an overly constraining approximation (Vallino et al., 2014) and can be easily relaxed if needed. The catalysts and reactions included in the metabolic network represent the capabilities of the entire microbial community, but the reactions are distributed across $n_{\mathcal{g}}$ catalysts ( 8 for the case of Siders Pond, Figure 1), just as functions are distributed across phyla in natural communities (Vallino, 2003). The reactions are highly simplified and condensed, and consist of two essential components: an anabolic reaction that synthesizes catalyst from environmental resources, and a catabolic reaction that provides free energy to drive the anabolic reaction forward. A highly simplified list of metabolic reactions for the Siders Pond model is given in Table 2. To convey the basic ideas, we consider below the phyla responsible for sulfate reduction for chemotrophy and phytoplankton for phototrophy.

\section{chemotrophyh}

The catalyst $\mathcal{E}_{S R B}$ represents the capabilities of sulfate reducing bacteria (SRB) that oxidize labile organic matter, $C_{L}$, using sulfate as the electron acceptor. The anabolic and catabolic reactions are given by,

$$
\begin{aligned}
C_{L} & +\gamma_{\mathcal{S}} \mathrm{NH}_{3}+\delta_{\xi} \mathrm{H}_{3} \mathrm{PO}_{4}+a_{1, S R B}^{A} \mathrm{H}_{2} \mathrm{SO}_{4} \rightarrow S_{S R B} \\
& +a_{1, S R B}^{A} \mathrm{H}_{2} \mathrm{~S}(a q)+b_{1, S R B}^{A} \mathrm{H}_{2} \mathrm{O} \\
C_{L} & +\frac{1}{2} \mathrm{H}_{2} \mathrm{SO}_{4} \rightarrow \mathrm{H}_{2} \mathrm{CO}_{3}+\frac{1}{2} \mathrm{H}_{2} \mathrm{~S}(a q),
\end{aligned}
$$

respectively, where the stoichiometric coefficients, $a_{1, S R B}^{A}$ and $b_{1, S R B}^{A}$, are determined from elemental balances around $\mathrm{O}$ and $\mathrm{H}$. Both reactions above must be catalyzed by $\xi_{S R B}$, so the reaction rates are proportional to the concentration of the catalyst, $c_{\mathcal{S}_{S R B}}$, present (note, we also use bracket nomenclature, [ $\left.\mathfrak{\xi}_{S R B}\right]$, for concentration below). These two reactions can be combined by introducing a reaction efficiency variable, $\varepsilon_{S R B}$, to produce an overall reaction representing growth and respiration of sulfate reducing bacteria, $r_{1, S R B}$, given by,

$$
\begin{aligned}
C_{L} & +\varepsilon_{S R B}\left(\gamma_{\mathcal{g}} \mathrm{NH}_{3}+\delta_{\mathcal{g}} \mathrm{H}_{3} \mathrm{PO}_{4}\right) \\
& +\left(\frac{1}{2}+\varepsilon_{S R B}\left(a_{1, S R B}^{A}+\frac{1}{2}\right)\right) \mathrm{H}_{2} \mathrm{SO}_{4} \rightarrow \varepsilon_{S R B} \mathfrak{g}_{S R B} \\
& +\left(1-\varepsilon_{S R B}\right) \mathrm{H}_{2} \mathrm{CO}_{3}+\left(\frac{1}{2}+\varepsilon_{S R B}\left(a_{1, S R B}^{A}+\frac{1}{2}\right)\right) \mathrm{H}_{2} S(a q) \\
& +\varepsilon_{S R B} b_{1, S R B}^{A} \mathrm{H}_{2} \mathrm{O} .
\end{aligned}
$$

The reaction efficiency variable, $\varepsilon_{S R B}$, is one of two classes of optimal control variables and a central design feature of the MEP model. As $\varepsilon_{S R B}$ approaches 1, Equation (3) represents $100 \%$ conversion of labile carbon plus $\mathrm{N}$ and $\mathrm{P}$ resources to catalyst, while as $\varepsilon_{S R B}$ approaches 0 , the reaction changes to $100 \%$ anaerobic combustion of labile carbon. From an entropy production perspective, only the catabolic reaction dissipates significant free energy, so $\varepsilon_{S R B}$ should be set to zero to maximize entropy production; however, the catabolic reaction cannot proceed without catalyst. There exists, then, an optimum value of $\varepsilon_{S R B}$ that produces just enough $\mathcal{E}_{S R B}$ catalyst to dissipate the chemical potential between $\mathrm{C}_{\mathrm{L}}$ and $\mathrm{H}_{2} \mathrm{SO}_{4}$, but $\varepsilon_{S R B}$ must change as a function of $\mathrm{C}_{L}$ and $\mathrm{H}_{2} \mathrm{SO}_{4}$ supply rates as well as $\mathrm{N}$ and $\mathrm{P}$ availability. Conceptually, the MEP problem is to determine how $\varepsilon_{S R B}$ should change over time and space to maximize free energy dissipation; however, there are a few other important details.

Gibbs free energies of reaction, $\Delta_{r} G_{i, j}$, are calculated using Alberty's (2003) approach, which accounts for substrate activities, $\mathrm{pH}$ and temperature. For chemotrophic reactions, an adaptive Monod equation parameterized by $\varepsilon_{j}$ accounts for the tradeoffs between substrate affinity, maximum specific growth rate and growth efficiency and can approximate oligotrophic to copiotrophic growth kinetics by varying $\varepsilon_{j}$ between 0 and 1 (Algar and Vallino, 2014; Vallino et al., 2014). In addition to this kinetic constraint, $F_{K}$, reaction rates, $r_{i, j}$, are also constrained by reaction thermodynamics, $F_{T}$, as described by La Rowe et al. (2012). Consequently, the rates of chemotrophic reactions take the following general form,

$$
r_{i, j}=v^{*} \varepsilon_{j}^{2} \Omega_{i, j}\left[\mathscr{g}_{j}\right] F_{K}\left(\mathbf{c}, \varepsilon_{j} ; \kappa^{*}\right) F_{T}\left(\triangle_{r} G_{i, j}\right),
$$

where $\mathbf{c}$ are substrate concentrations, $v^{*}$ and $\kappa^{*}$ are universal constants and $\Omega_{i, j}$ is the second optimal control variable class. Since each catalyst, $\dot{g}_{j}$, can catalyze $n_{r, j}$ sub-reactions (Table 2), $\Omega_{i, j}$ determines the fraction of catalyst $j, \xi_{j}$, that is allocated to reaction $r_{i, j}$. For instance, the sulfate reducing bacteria have two others reactions in addition to $r_{1, S R B}$, Equation (3) (Table 2). Reactions $r_{2, S R B}$ and $r_{3, S R B}$ allow SRB to decompose recalcitrant organic carbon, $C_{D}$, and phosphorous, $P_{D}$, into labile organic carbon, $C_{L}$, and inorganic phosphate, respectively, and $\Omega_{i, S R B}$ determines the fraction of protein allocated to each of the three reactions. Consequently, each $\Omega_{i, j}$ is bound between 0 and 1 , and $\Omega_{i, j}$ must sum to unity over all $i$ for each catalyst; that is, 
TABLE 1 | Names of state variables and associated symbols.

\begin{tabular}{|c|c|c|c|}
\hline Variable & Sym. & Variable & Sym. \\
\hline Salt & $c_{S a l}$ & Phytoplankton & ${ }^{c} \mathcal{G}_{\text {Phy }}$ \\
\hline Dissolved oxygen & $c_{\mathrm{O}_{2}}$ & Green sulfur bacteria & ${ }^{c} \mathcal{g}_{G S B}$ \\
\hline Dissolved inorganic carbon & $\mathrm{C}_{\mathrm{H}_{2} \mathrm{CO}_{3}}$ & Aerobic predators & ${ }^{c} \xi_{G z}$ \\
\hline Inorganic phosphate & $\mathrm{C}_{\mathrm{H}_{3} P \mathrm{P}_{4}}$ & Anaerobic predators & ${ }^{c} \mathcal{G}_{A G z}$ \\
\hline Sulfate & $\mathrm{C}_{\mathrm{H}_{2} \mathrm{SO}_{4}}$ & Aerobic organoheterotrophic bacteria & ${ }^{c} \mathcal{g}_{B a c}$ \\
\hline Hydrogen sulfide & $\mathrm{CH}_{2} \mathrm{~S}$ & Sulfate reducing bacteria & ${ }^{c} \xi_{S R B}$ \\
\hline Phytoplankton carbohydrates & ${ }^{c} C_{\text {Phy }}$ & Photoheterotrophs & ${ }^{c} g_{P H}$ \\
\hline Green sulfur bacteria carbohydrates & ${ }^{c} C_{G S B}$ & Sulfide oxidizing bacteria & ${ }^{c} \mathcal{G}_{S O x}$ \\
\hline Labile organic carbon & $c^{c} C_{L}$ & & \\
\hline Refractory organic carbon & ${ }^{c} C_{D}$ & & \\
\hline Refractory organic phosphate & ${ }^{c} P_{D}$ & & \\
\hline
\end{tabular}

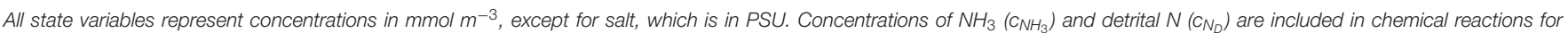
stoichiometric and thermodynamic calculations, but were held constant at 5 and $10 \mathrm{mmol} \mathrm{m}$, respectively, in all simulations.

TABLE 2 | Reactions associated with the 8 biological catalysts, $\mathcal{S}_{j}$, used to model microbial biogeochemistry in Siders Pond, where $r_{i, j}$ represents sub-reaction $i$ of biological catalyst $\mathcal{G}_{j}$.

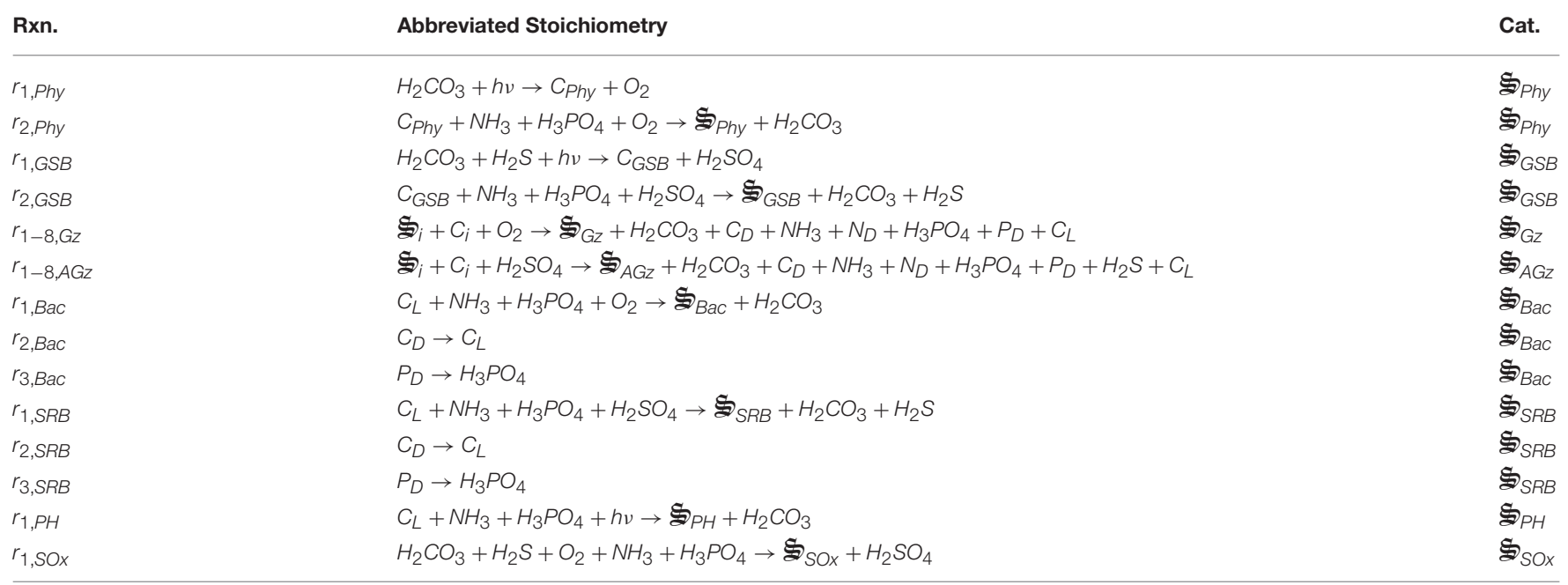

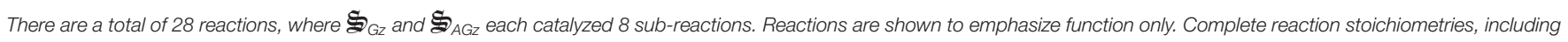
influence of optimal control variables, are given in section 2.7 of the Supplementary Material. See caption of Figure 1 for nomenclature.

$\sum_{i=1}^{n_{r, j}} \Omega_{i, j}=1$. An example of how $F_{K}, \Delta_{r} G_{i, j}$, and $F_{T}$ vary over time and space to influence reaction rates of sulfate reducing bacteria is given in Supplementary Material 4.1, Figure S3.

\section{phototrophy}

In this version of the MEP model we introduce catalysts associated with phototrophic growth, specifically phytoplankton (Phy), $\mathcal{E}_{\text {Phy, }}$ anaerobic green sulfur bacteria (GSB), $\mathcal{E}_{G S B}$, and photoheterotrophs $(\mathrm{PH}), \boldsymbol{S}_{P H}$. Both Phy and GSB are modeled similarly using two sub-reactions (Table 2). One subreaction couples photon capture that drives $\mathrm{CO}_{2}$ fixation into carbohydrates, $C_{P h y}$ and $C_{G S B}$, and a second sub-reaction converts carbohydrates into biomass in a manner analogous to growth of chemotrophs described above. We focus on phytoplankton here because development for GSB is similar, and can be found in the Supplementary Material.

The carbon fixation reaction for phytoplankton is given by,

$$
\varepsilon_{P h y} \mathrm{H}_{2} \mathrm{CO}_{3}+n_{1, P h y} h v \rightarrow \varepsilon_{P h y}\left(\mathrm{C}_{P h y}+\mathrm{O}_{2}(a q)\right)
$$

where $h v$ are captured photons of frequency $v, h$ is Plank's constant and $n_{1, P h y}$ is the moles of photons needed to fix 1 mole of $\mathrm{CO}_{2}$ at $100 \%$ efficiency (i.e., $\varepsilon_{\text {Phy }}=1$ ). The Gibbs free energy for a mole of photons is given by

$$
\triangle_{r} G_{\gamma}=-\eta_{I} h \nu N_{A}
$$

where $N_{A}$ is Avogadro's number and $\eta_{I}$ is the thermodynamic efficiency for converting electromagnetic radiation into work 
(Candau, 2003). If $\Delta_{r} G_{C_{P h y}}$ is the Gibbs free energy for fixing a mole of $\mathrm{H}_{2} \mathrm{CO}_{3}$ into $\mathrm{C}_{\mathrm{Phy}}$ plus $\mathrm{O}_{2}$, then moles of photons needed to fix 1 mole of $\mathrm{CO}_{2}$ is given by,

$$
n_{1, P h y}=-\frac{\triangle_{r} G_{C_{P h y}}}{\triangle_{r} G_{\gamma}},
$$

and the Gibbs free energy of reaction for $\mathrm{CO}_{2}$ fixation defined by Equation (5) is given by,

$$
\triangle_{r} G_{1, P h y}=-\left(1-\varepsilon_{P h y}\right) \triangle_{r} G_{C_{P h y}} .
$$

In this formulation, $\varepsilon_{P h y}$ governs the efficiency for the conversation of electromagnetic potential into chemical potential. If $100 \%$ of photosynthetic active radiation is converted to chemical potential, no entropy is produced, and the free energy of reaction for Equation (5) is zero, so the reaction will not proceed due to thermodynamic constraints. However, as $\varepsilon_{P h y}$ is decreased, some photons are dissipated as heat, which drives the reaction forward, and all photons are dissipated as heat when $\varepsilon_{\text {Phy }}=0$, but no catalyst is synthesized.

The reaction rate for $\mathrm{CO}_{2}$ fixation depends on the rate of photon capture, which is given by,

$$
\Delta I_{P h y}=k_{p} \Omega_{1, P h y}\left[\dot{\xi}_{P h y}\right] I(t, z)
$$

where $k_{p}$ is the coefficient for light absorption by particles, $\Omega_{1, P h y}\left[\mathcal{G}_{P h y}\right]$ is the fraction of phytoplankton catalytic machinery allocated to capturing photons (i.e., chlorophyll and electron transfer proteins), and $I(t, z)$ is light intensity (mmol photons $\mathrm{m}^{-2} \mathrm{~d}^{-1}$ ) at time $t$ and depth $z$. Consequently, the reaction rate for $\mathrm{CO}_{2}$ fixation is given by,

$$
r_{1, P h y}=\frac{\triangle I_{P h y}}{n_{1, P h y}} F_{K}\left(\mathbf{c}, \varepsilon_{j} ; \kappa^{*}\right) F_{T}\left(\triangle_{r} G_{1, P h y}\right),
$$

where $F_{K}$ and $F_{T}$ are the kinetic and thermodynamic drivers, respectively. This reaction has similarities to those typically used to describe phytoplankton growth (Macedo and Duarte, 2006), but our derivation focuses not on the local light intensity level, but rather on how much light is actually intercept by the phytoplankton, as governed by $k_{p} \Omega_{1, P h y}\left[\dot{\xi}_{P h y}\right] I$, and how much of that free energy is actually used to drive carbon fixation, as governed by $\varepsilon_{P h y}$. As evident in Equation (10), the maximum rate is directly tied to the rate of photon interception, $\Delta I_{P h y}$, not by an arbitrary maximum specific growth parameter. The second reaction used by Phy and GSB (Table 2) is simply the conversion of reduced organic carbon, $C_{P h y}$ and $C_{G S B}$, into more catalyst or $\mathrm{CO}_{2}$ depending of the value of $\varepsilon_{P h y}$.

The reaction for photoheterotrophs $(\mathrm{PH})$ differs slightly from that above. In this case only one reaction is used $\left(r_{1, P H}\right.$, Table 2$)$, where photon capture is linked to the conversion of labile carbon into $\mathrm{PH}$ catalyst. As above, photons captured can also be dissipated as heat for $\varepsilon_{P H}<1$, or the free energy can be used to drive biosynthesis $\left(\varepsilon_{P H}>0\right)$, where photon free energy replaces chemical free energy used in chemotroph reactions.

\section{Transport Model}

Siders Pond is horizontally well mixed, so an advectiondispersion-reaction (ADR) model that includes particle sinking was used to approximate vertical transport of the 19 state variables (Figure 1). The origin of the vertical coordinate, $z$, is defined at the pond's surface, and the axis points in the positive direction downward toward the benthos and reaches a maximum depth of $15 \mathrm{~m}$. Siders Pond 3D bathymetry surface was rendered from a contour plot in Caraco (1986), and an equation for cross-section area as a function of depth was derived therefrom (Figure S1). Equations for vertical volumetric flow rate, lateral groundwater inputs and seawater intrusion at the bottom boundary were derived from Caraco (1986), who used both tritium-helium-3 dating combined with mass balance calculations to estimate freshwater inputs and seawater intrusion. An equation for the dispersion coefficient was derived by fitting simulated salinity profiles to observations collected during this study.

The primary external drivers in the model are temperature, $\mathrm{pH}$ and photosynthetic active radiation. Surface irradiance was based on a model of solar zenith angle (Brock, 1981), which assumes a cloudless sky. To predict PAR light intensity as function of time and depth, a standard light adsorption model was used that includes coefficients for light absorption by water, $k_{w}$, and particulate material, $k_{p}$.

Neumann boundary conditions were used for state variables at the pond's surface and gas transport for $\mathrm{O}_{2}, \mathrm{CO}_{2}$, and $\mathrm{H}_{2} \mathrm{~S}$ across the air-water interface was accounted for using a stagnant-film model. Robin boundary conditions were used for the bottom boundary based on the flux of material entering the boundary associated with the intrusion of seawater diluted with groundwater. In addition, aerobic and anaerobic decomposition of sinking organic matter from the water column contributed to a sink for $\mathrm{O}_{2}$ and $\mathrm{H}_{2} \mathrm{SO}_{4}$, and a source for $\mathrm{H}_{3} \mathrm{PO}_{4}, \mathrm{H}_{2} \mathrm{CO}_{3}$, and $\mathrm{H}_{2} \mathrm{~S}$ to the overlying water.

\section{Entropy Production and Optimization Entropy-production}

Entropy production occurs when an energy potential is destroyed and dissipated as heat to the environment, but not when the potential is converted to another potential. For example, a flame converting chemical potential into heat or light being absorbed by water both result in maximum entropy production; these are irreversible processes and the Gibbs free energy is destroyed. On the other hand, entropy is not produced if electromagnetic potential is converted reversibly into chemical potential, but thermodynamic theory requires that reversible reactions must proceed infinitely slowly. In the model, as the reaction efficiency for phytoplankton, $\varepsilon_{P h y}$, approaches 1, electromagnetic potential is converted to chemical potential without entropy production, but the thermodynamic force, $F_{T}$, drivers the reaction rate to 0 , and as $\varepsilon_{P h y}$ approaches zero, all electromagnetic potential is dissipated as heat, but no catalyst is produced, as evident in Eq. (5). Consequently, living organisms operate between these two extremes. For organisms to grow at a non-zero rate, an energy potential must be partially dissipated and some entropy must be produced. 
Instantaneous entropy production per unit volume, $\dot{\sigma}_{i, j}$, for chemotrophic reactions is readily calculated as the product of reaction rate times Gibbs free energy of reaction (Vallino, 2010) divided by temperature, $T$, as given by,

$$
\dot{\sigma}_{i, j}=-\frac{1}{T} \triangle_{r} G_{i, j} r_{i, j} .
$$

Average entropy production, $\left\langle\dot{\sigma}_{i, j}\right\rangle$, is calculated by integrating $\dot{\sigma}_{i, j}$ over an interval of time, $\Delta t$, as given by,

$$
\left\langle\dot{\sigma}_{i, j}\right\rangle=\frac{1}{\Delta t} \int_{t}^{t+\Delta t} \dot{\sigma}_{i, j} d \tau .
$$

The value of $\Delta t$ is unknown, but it is the fundamental parameter of interest in this study, because it represents the time scale over which biology has evolved to operate.

Entropy production associated with the dissipation of electromagnetic radiation is readily calculated from the Gibbs free energy for photons, Equation (6), and photon capture rate, Equation (9). The photon free energy can be dissipated as heat along two pathways: (1) interception by water or (2) particles, such as bacteria and grazers, as well as by the non-photosynthetic components of phytoplankton. Photons intercepted by the photosynthetic machinery of phototrophs can be either dissipated as heat, if $\varepsilon_{j}=0$, or all energy potential can be transferred to chemical potential, if $\varepsilon_{j}=1$, but typically it is a combination of both, so that $0<\varepsilon_{j}<1$. Consequently, total entropy production, $\dot{\sigma}_{\Sigma}$, is the sum of three processes: entropy production by light absorption by water, $\dot{\sigma}_{W}$, entropy production by light absorption by particles, $\dot{\sigma}_{P}$, and entropy production by chemical reactions, $\dot{\sigma}_{R}$, including photoreactions. All entropy production terms are accounted for in the MEP optimization problem, including that from light absorption by water and particles.

\section{MEP-optimization}

The stoichiometry, thermodynamics and kinetics of the 28 reactions that comprise the metabolic network (Table 2, Figure 1) vary as a function of the eight $\varepsilon_{j}$ optimal control variables, and the partitioning of biological structure, $\dot{\varepsilon}_{j}$, to sub-reactions $r_{i, j}$ that depends on the values of the $\Omega_{i, j}$ control variables, of which there are 20. A solution to the MEP model, and associated microbial biogeochemistry, is determined by adjusting $\varepsilon_{j}$ and $\Omega_{i, j}$ over $\Delta t$ time and $1 \mathrm{D}$ space to maximize entropy production, the details of which are provided in Supplementary Material section 3.2, but also see Vallino et al. (2014). As $\Delta t$ approaches 0 in Equation (12), the average entropy production, $\left\langle\dot{\sigma}_{i, j}\right\rangle$, approaches the instantaneous value, $\dot{\sigma}_{i, j}$, and describes abiotic processes based on our hypothesis. Increasing $\Delta t$ permits other solutions that are not constrained to the steepest descent trajectory. By changing values of $\varepsilon_{j}$ and $\Omega_{i, j}$ over time and space, pathways that avoid the ditch halfway down the hill are allowed, or strategies that anticipate the sun rising in the morning can be exploited. The critical aspect of the optimization is choosing the appropriate time interval over which to maximize entropy production and whether local or global optimization should be used (Vallino, 2011); consequently, these two aspects are the focus of this manuscript and form the bases of the Results section.

\section{Physical parameters and model skill assessment}

If the MEP model developed here were cast as a conventional biogeochemistry model, there would be 89 biological parameters associated with growth kinetics. Instead, there are 28 optimal control (OC) variables ( $8 \varepsilon_{j}$ and $20 \Omega_{i, j}$ ), but only one biological parameter, because the OC variables are determined by maximizing entropy production described above. The sole biological parameter, $\Delta t$, specifies the time scale over which entropy is maximized, Equation (12), and its impact on solution dynamics is the focus of this manuscript. There are 11 uncertain physical parameters, 9 associated with particulate matter sinking velocities and two associated with light absorption by water and particles. Since fitting model output to observations is not an indication of good model forecasting fidelity, we only crudely adjusted the 11 physical parameters so that model outputs were within an order of magnitude of observations. These adjustments were made with fix values of the 28 OC variables that were set arbitrarily. The objective was to get the physics to reasonably approximate that occurring in Sider Pond.

To determine model performance, 2D linear interpolation was used to extract values of model state variables at times and depths corresponding to those taken for observations. Root mean squared errors were then calculated between interpolated model outputs and observations to quantify model skill (Fitzpatrick, 2009). The computational approach used for solving the $1 \mathrm{D}$ advection-dispersion-reaction equation is described in Supplementary Material section 2.9 and the approach used for solving the optimal control problem is described in Supplementary Material section 3.2.

\section{RESULTS}

All solutions presented here are from local entropy maximization at 10 depths $(0,1,2,3,4,6,8,10,12$, and $15 \mathrm{~m})$. We investigated two optimization time intervals, $\Delta t$, for entropy maximization, a short interval of 0.25 days and a long interval of 3 days. Simulations were started on May 19th, but only the last 6 days of simulations from Jun 21st to Jun 27th are shown here and compared to observations collected on Jun 25th and 26th (Figure 2). Our results focus on how these two solutions compare to observations in the Simulations Compared to Observations section as well as how the short and long interval optimization windows differ from each other in the Comparison Between SIO and LIO Simulations section.

\section{Simulations Compared to Observations}

Solutions obtained from the short (0.25 day) and long (3 day) interval optimizations are compared to biogeochemical observations from Siders Pond that were collected to form a 2D sample grid on Jun 25th and 26th, 2015 (Figure 2). Simulated profiles for photosynthetic active radiation (PAR), Chl a and dissolved oxygen (DO) are compared to observations in Siders Pond in Figure 3. The short interval optimization (SIO) shows PAR extending to nearly the bottom of the pond (Figure 3A), 


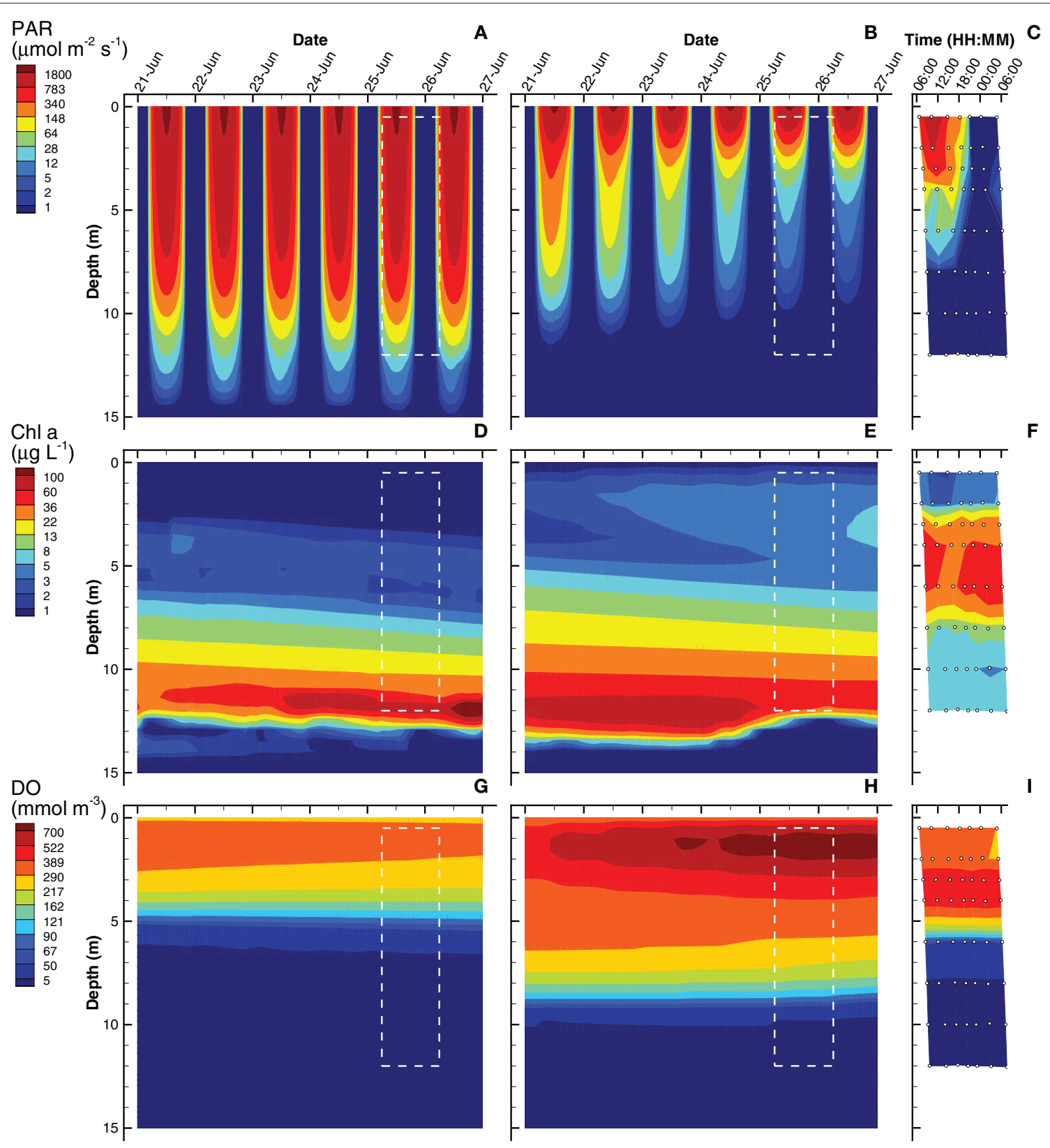

FIGURE 3 | Contour plots of photosynthetic active radiation (PAR) (A-C), chlorophyll (Chl) a concentration (D-F) and dissolved oxygen (DO) (G-I) for six day simulations using short interval optimization (SIO) (left column), long interval optimization (LIO) (center column) and for observations collected from Siders Pond over a $24 \mathrm{~h}$ period on Jun 25 to Jun 262015 (right column). Rectangle (dashed white lines) in simulation plots corresponds to time and depths where observations are comparable (i.e., Jun 25/26, 0.5 to $12 \mathrm{~m}$ ). Actual observations are shown as white circles with black perimeters (see also Figure 2).

while PAR from the long interval optimization (LIO) (Figure 3B) more closely matches observations (Figure $\mathbf{3 C}$ ). The prediction for $\mathrm{Chl}$ a in both simulations do not match observations very well (Figures 3D-F), but this is partially due to how Chl a was estimated, since $\mathrm{Chl}$ a is not specifically modeled. The $\mathrm{Chl}$ a in vivo observations show a peak $\mathrm{Chl}$ a around $5 \mathrm{~m}$, while both simulations have peaks around $12 \mathrm{~m}$, but those peaks are due to accumulation of sinking phytoplankton rather than productivity at that depth. The LIO simulation does show a secondary Chl a peak developing around $3 \mathrm{~m}$, but it is weaker than observations $\left(\sim 6\right.$ vs. $\left.40 \mu \mathrm{g} \mathrm{L}^{-1}\right)$. Based on DO, the SIO shows anaerobic conditions begin at $6 \mathrm{~m}$, while the LIO shows that occurring at $10 \mathrm{~m}$. The observed transition to anoxia splits between the two simulations at $8 \mathrm{~m}$. Observations also show a subsurface DO maximum at $3.5 \mathrm{~m}$, while both simulations show max DO closer to $1.3 \mathrm{~m}$. Furthermore, the SIO shows a decreasing DO max with time, while the LIO shows an increase over time, and the maximum reaches $800 \mathrm{mmol} \mathrm{m}^{-3}$ vs. 480 for observations. 
In general, the SIO simulations show less phototrophic activity while LIO shows greater activity than what the observations indicate. The LIO solutions show better fits to observations for PAR and Chl a based on RMSE, while the SIO shows a better fit to DO (Table 3).

Simulations of substrate concentrations for autotrophs, namely inorganic phosphate and dissolved inorganic carbon (DIC), show qualitative agreement to observations for both SIO and LIO solutions (Figure 4), but some discrepancies are apparent. The phosphate chemoclines occur around 10, 11 , and $8 \mathrm{~m}$ for the SIO, LIO, and observations, respectively (Figures 4A-C). Above the phosphate chemocline, the SIO simulation shows slightly elevated levels of $\mathrm{H}_{3} \mathrm{PO}_{4}(\sim 0.3 \mathrm{mmol}$ $\mathrm{m}^{-3}$ ) in the surface and $5 \mathrm{~m}$ layers, compare to observations (Figure 4C), which are near the level of detection $(0.03 \mathrm{mmol}$ $\mathrm{m}^{-3}$ ) except for a few spikes. Below the phosphate chemocline, observations show slightly higher accumulations of phosphate, approaching $22 \mathrm{mmol} \mathrm{m}^{-3}$, while the SIO and LIO simulations show max concentrations closer to 16 and $19 \mathrm{mmol} \mathrm{m}^{-3}$, respectively. For DIC, both SIO and LIO simulations show much lower DIC concentrations below $10 \mathrm{~m}$ (3,000 and 5,400 $\mathrm{mmol} \mathrm{m}{ }^{-3}$, respectively) than observed in Siders Pond $(16,500$

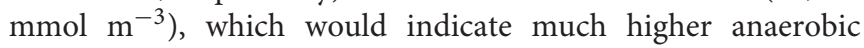
remineralization in the pond than occurs in the simulations. The SIO and LIO also show greater draw down of DIC in the surface water above 2 and $4 \mathrm{~m}$ respectively, and the LIO simulation shows minimum DIC approaching just $2 \mathrm{mmol} \mathrm{m}^{-3}$ at $1 \mathrm{~m}$, while minimum observed value is above $660 \mathrm{mmol} \mathrm{m}^{-3}$. The SIO simulation fits phosphate observations slight better than the LIO simulation, but LIO does better at fitting the DIC observations (Table 3).

Simulations of hydrogen sulfide show a chemocline at approximately 9 and $10 \mathrm{~m}$ for the SIO and LIO solutions, respectively, which are slightly deeper than the $\mathrm{H}_{2} \mathrm{~S}$ chemocline observed in Siders Pond at about $8 \mathrm{~m}$ (Figures 5A-C). However, $\mathrm{H}_{2} \mathrm{~S}$ reaches concentrations as high as $7,000 \mathrm{mmol} \mathrm{m}^{-3}$ in Siders Pond, while maximum concentrations only reach 900 and $2,100 \mathrm{mmol} \mathrm{m}{ }^{-3}$ in the SIO and LIO simulations, respectively. Simulations also show a peak $\mathrm{H}_{2} \mathrm{~S}$ concentration at $12 \mathrm{~m}$, and a decrease in concentration below $12 \mathrm{~m}$, which also indicates lower anaerobic respiration in the simulations. Simulated sulfate concentrations in the upper portion of the water column $(0$ to $4 \mathrm{~m}$ ) are similar to those observed (Figures 5D,E), but the simulations show an abrupt sulfate chemocline starting at about $8 \mathrm{~m}$, while observations show a more gradual increase in sulfate with depth. Furthermore, sulfate reaches much higher concentrations in the simulations at depth than do observations, showing maximums of $15,500 \mathrm{mmol} \mathrm{m}^{-3}$ in both simulations, while observation maximum is only $9,000 \mathrm{mmol} \mathrm{m}^{-3}$. The lower simulated concentrations of $\mathrm{H}_{2} \mathrm{~S}$ and the higher simulated sulfate concentrations indicate that sulfate reduction in the model is lower than that actually occurring in Siders Pond, but the LIO simulations fit observations better for both $\mathrm{H}_{2} \mathrm{~S}$ and $\mathrm{H}_{2} \mathrm{SO}_{4}$ than do the SIO simulations (Table 3).

The last of the observations are dissolved organic carbon (DOC) and particulate organic carbon (POC) concentrations (Figure 6). For simulations, DOC is a derived quantity based on the sum of state variables $\left[C_{L}\right]$ and $\left[C_{D}\right]$, while POC is derived from the sum of internal carbohydrate stores, $\left[C_{P h y}\right]$ and $\left[C_{G S B}\right]$, plus the concentrations of all biological structures, $\left[\dot{\xi}_{j}\right]$. In the water column above $12 \mathrm{~m}$, the SIO simulation shows very low concentrations of DOC $\left(\sim 1 \mathrm{mmol} \mathrm{m}{ }^{-3}\right)$, but then increases rapidly to a maximum of $1,900 \mathrm{mmol} \mathrm{m}^{-3}$ (Figure 6A). The LIO simulation shows a similarly high DOC concentration at $14 \mathrm{~m}$, but above $12 \mathrm{~m}$, the DOC concentration ranges from 2 to $140 \mathrm{mmol} \mathrm{m} \mathrm{m}^{-3}$, which is closer to those observed in Siders Pond, which range from 200 to $300 \mathrm{mmol} \mathrm{m}^{-3}$ above $10 \mathrm{~m}$, and increase to a maximum of about $1,000 \mathrm{mmol} \mathrm{m}^{-3}$ at $12 \mathrm{~m}$. Similar to DOC, POC in the SIO simulation shows low values $\left(<30 \mathrm{mmol} \mathrm{m}{ }^{-3}\right)$ above $6 \mathrm{~m}$, but POC peaks to $1,000 \mathrm{mmol}$ $\mathrm{m}^{-3}$ at $12 \mathrm{~m}$ (Figure 6D). The POC concentrations from the LIO simulation are closer to observations, but the mid-water POC maximum in the LIO simulation is approximately 500 mmol m $\mathrm{m}^{-3}$, while the observations peak at $280 \mathrm{mmol} \mathrm{m}^{-3}$ around $4 \mathrm{~m}$. Like the SIO simulation, the LIO simulation also shows high POC concentrations below $10 \mathrm{~m}$, which was not observed in Siders Pond. It is possible that DOC and POC may reach higher concentrations in the funnel-like basin of Siders Pond below $12 \mathrm{~m}$, but samples were not collected there. While the LIO simulations show better fit to DOC observations, the SIO simulations fit the POC observations better (Table 3). Overall, the LIO simulations fit six observations better, while the SIO simulations of fit three observations better, which indicates the LIO simulations are overall closer to observations (Table 3). On a qualitative measure, the LIO simulation produces a phytoplankton bloom near the surface of the pond (Figure 3), which is consistent with multiple years of student collected observations from Sider Pond. In that regard, the LIO solution appears better at predicting this important feature of Siders Pond.

\section{Comparison Between SIO and LIO Simulations}

Since the MEP optimization model generates a large number of outputs, this section highlights some of those outputs to contrast the simulations based on the short $(0.25 \mathrm{~d})$ interval optimization (SIO) to that from the long ( $3 \mathrm{~d}$ ) interval optimization (LIO). Consider entropy production, which is the variable that is being sequentially maximized over a $0.25 \mathrm{~d}$ interval (SIO) or a $3 \mathrm{~d}$ interval (LIO) at 10 different depths (Figure 7). Total entropy production, $\dot{\sigma}_{\Sigma}$, for the SIO and LIO simulations differ significantly, in that $\dot{\sigma}_{\Sigma}$ in the SIO solution is spread out over a $12 \mathrm{~m}$ water column (Figure 7A) vs. the LIO solution (Figure 7E), where most of the entropy production occurs in the top $3 \mathrm{~m}$ of the pond. Furthermore, peak entropy production in the LIO simulation is 7.5 times great than the SIO solution (9.8 vs. 1.3 GJ $\mathrm{m}^{-1} \mathrm{~K}^{-1} \mathrm{~d}^{-1}$ ), and the total integrated entropy produced over the water column and over the 6 day simulation, $\sigma_{T}$, was 21.3 GJ K $\mathrm{K}^{-1}$ and $36.5 \mathrm{GJ} \mathrm{K}^{-1}$ for the SIO and LIO simulations, respectively. For comparison, if the pond was sterile, $\sigma_{T}$ would equal $12.4 \mathrm{GJ} \mathrm{K}^{-1}$ from light absorption in the water column. The $71 \%$ higher total integrated entropy, $\sigma_{T}$, produced by the LIO simulation illustrates that extending the optimization time scale 
TABLE 3 | Root mean squared errors between model predictions and observations for the short (SIO, $t=0.25 \mathrm{~d})$ and long (LIO, $t=3.0 \mathrm{~d})$ interval optimizations.

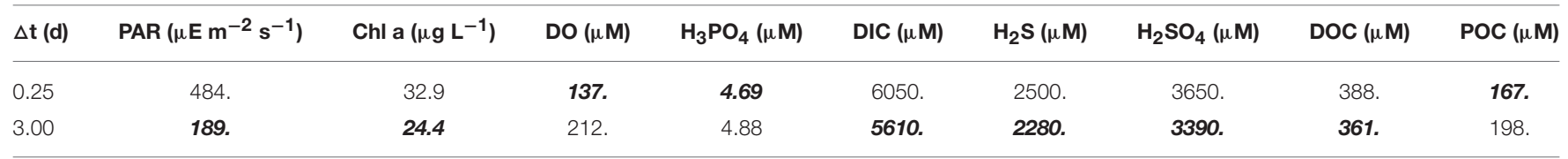

Better (i.e., lower) scores are highlighted in bold italic font face.

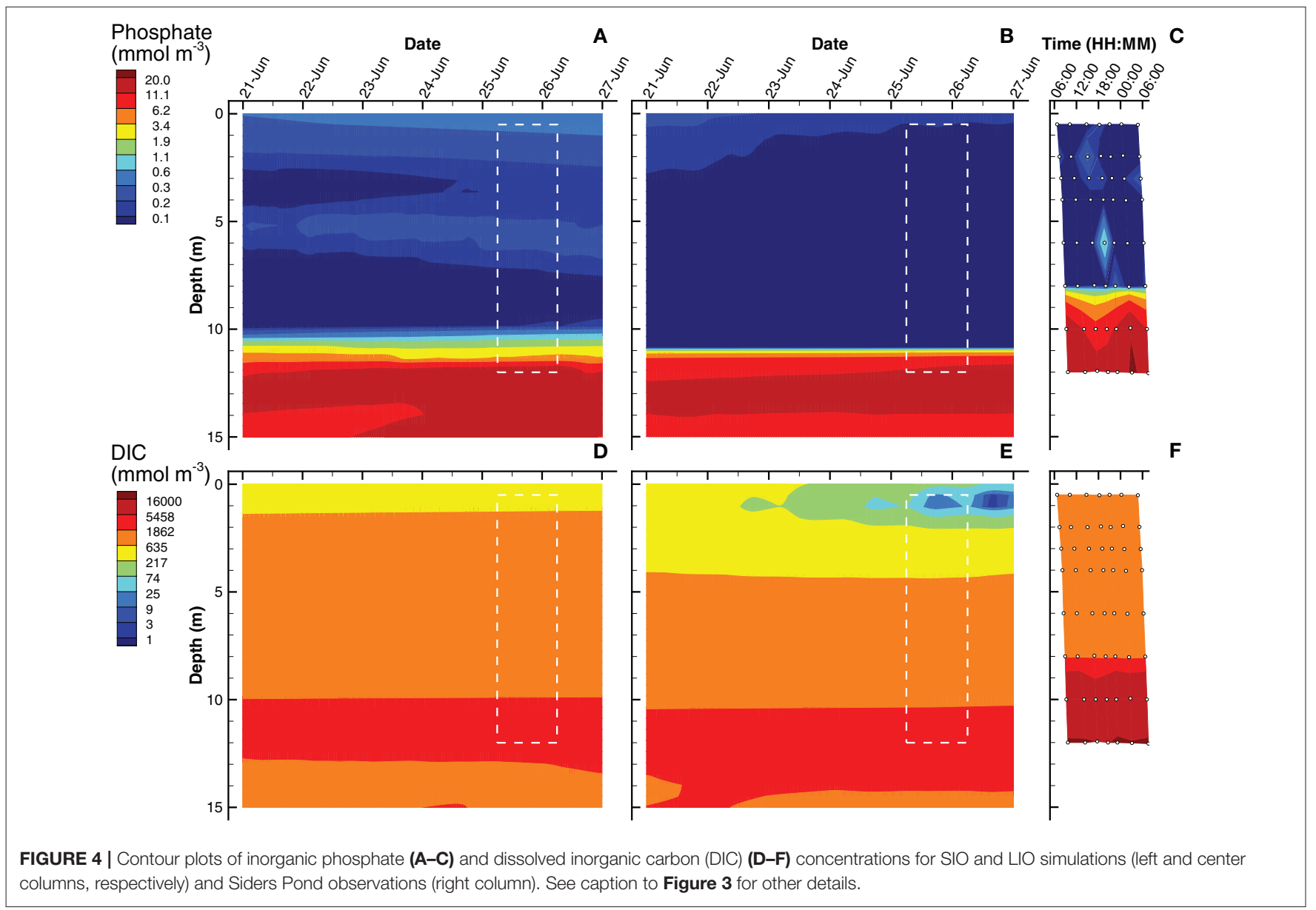

results in greater entropy production, which is consistent with a previous study (Vallino et al., 2014).

The different contributors to total entropy production, namely by reaction, $\dot{\sigma}_{R}$, water, $\dot{\sigma}_{W}$, and particles, $\dot{\sigma}_{P}$, also differ significantly between the two simulations. For instance, total integrated entropy production associated with reactions was actually greater in the SIO than the LIO simulation (Figure 7B vs. Figure $7 \mathbf{F}$ ), as well as exhibited a greater maximum $\dot{\sigma}_{R}$ ( 0.28 vs. $0.26 \mathrm{GJ} \mathrm{m}^{-1} \mathrm{~K}^{-1} \mathrm{~d}^{-1}$ for SIO versus $\mathrm{LIO}$ ); however, entropy production by reaction during the day is rather small $(<25 \%$ in the upper $5 \mathrm{~m}$ ) compared to light dissipation by water or particles, but the two simulations differ here as well. The SIO simulation dissipates most of the incoming radiation by water absorption in the upper $5 \mathrm{~m}$ of the water column (Figure 7C vs. Figure 7G), while the LIO simulation dissipates most of the electromagnetic potential via absorption by particles
(Figure 7D vs. Figure 7H). As evident in the POC (Figure 6) and $\mathrm{Chl}$ a (Figure 3) concentrations, the LIO simulation produces more biomass in the upper portion of the water column, and biomass is effective at absorbing and dissipating light.

An analysis of phytoplankton (Phy) growth by the SIO and LIO simulations (Figure 8) illustrates not only how the two simulations differ, but also some of the mechanics of the MEPbased optimization approach. Phytoplankton density attains a maximum of $20 \mathrm{mmol} \mathrm{m}^{-3}$ in the LIO simulation by June $27 \mathrm{th}$, but Phy are effectively absent in the SIO simulation, attaining a maximum of only $0.1 \mathrm{mmol} \mathrm{m}^{-3}$ (Figures $\mathbf{8 A}, \mathbf{F}$ ). While it is possible that the low phytoplankton density in the SIO simulation could be due to extensive predation, this is not the case because the rates of $\mathrm{CO}_{2}$ fixation $\left(r_{1, P h y}\right.$, Table 2$)$ and conversion of fixed $\mathrm{C}$ to biomass $\left(r_{2, P h y}\right.$, Table 2$)$ are two orders of magnitude 


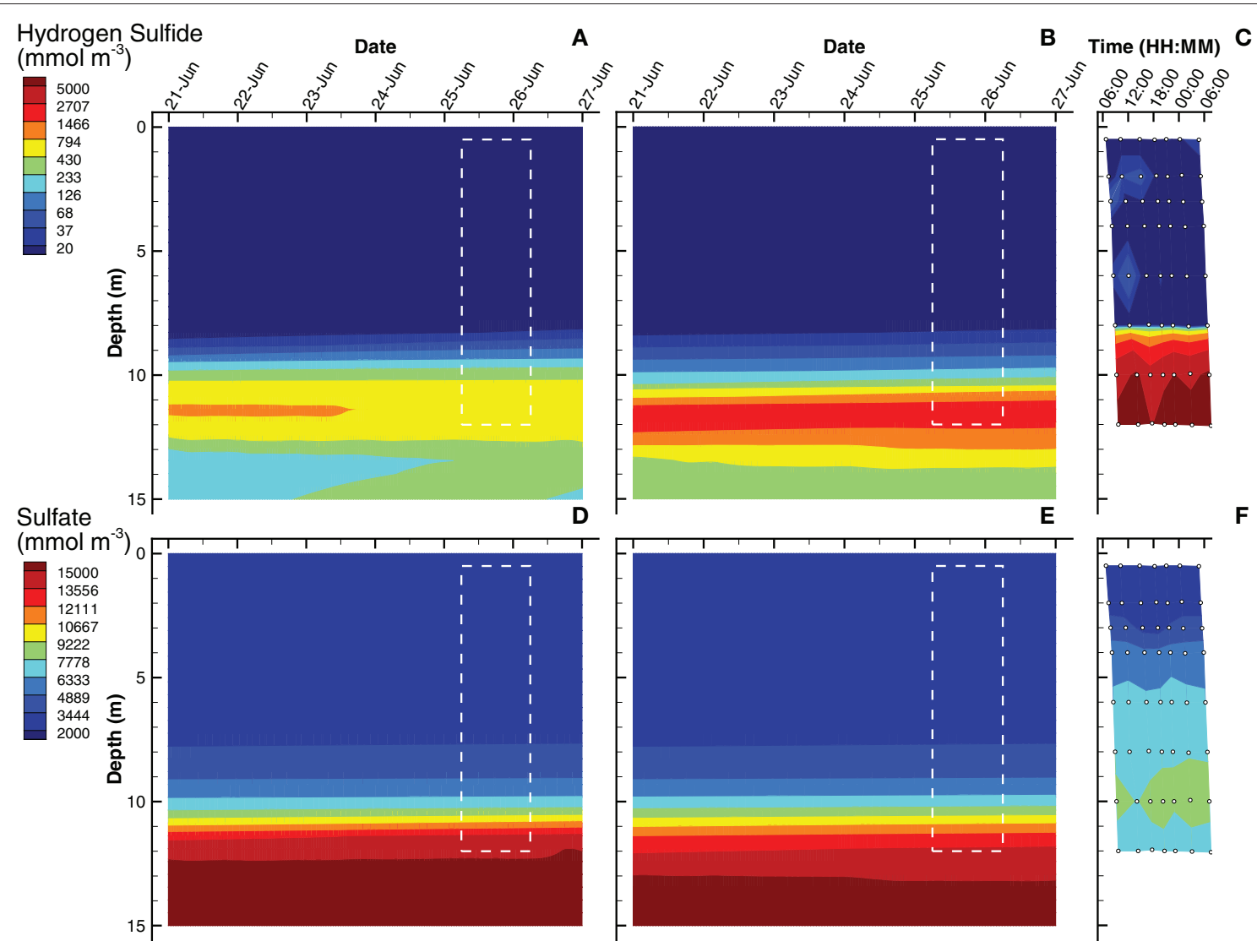

FIGURE 5 | Contour plots of hydrogen sulfide (A-C) and sulfate (D-F) concentrations for SIO and LIO simulations (left and center columns, respectively) and Siders Pond observations (right column). See caption to Figure $\mathbf{3}$ for other details.

lower in the SIO versus LIO simulation (Figures 8B,C vs. Figures $\mathbf{8 G}, \mathbf{H}$ ). The differences in phytoplankton density and reaction rates between the $\mathrm{SIO}$ and $\mathrm{LIO}$ simulations are due to how the optimal control variables change over time and space (Figures $\mathbf{8 D}, \mathbf{E}, \mathbf{I}, \mathbf{J}$ ). Consider how reaction efficiency, $\varepsilon_{P h y}$, varies over time and space in the two simulations (Figures 8D,I). The SIO simulation shows rapid switching between very high efficiencies $(>0.98)$ and very low efficiencies $(<0.02)$ over time. While not on all days, reaction efficiency drops to very low levels around noon (Figure 8D), which results in high entropy production, but at the sacrifice of fixing $\mathrm{CO}_{2}$, which is consistent with maximizing energy dissipation on a short term time scale. On the contrary, the LIO solution (Figure 8I) shows more gradual changes in $\varepsilon_{P h y}$, operating between 0.3 and 0.4 for most of the simulation. There is rapid changing of the biomass allocation variable, $\Omega_{1, P h y}$, in the LIO solution (Figure 8J), but this makes sense, because the control variable partitions phytoplankton biomass to the light requiring carbon fixation reaction, $r_{1, P h y}$, during peak daylight (Figure 8G), then switches to the biosynthesis reaction, $r_{2, P h y}$, at night (Figure $8 \mathbf{H}$ ). Based on Figure 7C, the SIO solution instead uses water for the short term dissipation of electromagnetic potential in the pond's surface, but in deeper water the SIO solution does produce biomass.
Instead of producing phytoplankton, the SIO solution produces more green sulfur bacteria (GSB), which reach a maximum concentration of $735 \mathrm{mmol} \mathrm{m}^{-3}$, compare to only 23 $\mathrm{mmol} \mathrm{m} \mathrm{m}^{-3}$ in the LIO solution (Figures 9A,D). Furthermore, GSB increase during the SIO simulation, while they decrease in the LIO, which is evident in the greater biosynthesis reaction, $r_{2, G S B}$, in SIO vs. LIO solutions (Figures $9 \mathbf{B}, \mathbf{E}$ ) as well as in $r_{1, G S B}$ (not shown). However, the value of the reaction efficiency control variable, $\varepsilon_{G S B}$, does switch to low values around noon on several days in the SIO simulation, which implies again the solution favors entropy production over growth (Figures 9C,F). This SIO simulation also favors much higher reaction rates of photoheterotrophs $(\mathrm{PH}), r_{1, P H}$, compared to the LIO solution, but interestingly, this does not lead to greater concentrations of PH biomass, $\dot{\varepsilon}_{P H}$ (Figure 10). The reason is because high rates for $\mathrm{PH}$ growth, $r_{1, P H}$, are coupled with extremely low values of growth efficiency, $\varepsilon_{P H}$ (Figures 10B,C). Based on the adaptive Monod equation that changes substrate affinity as a function of $\varepsilon_{P H}^{4}$, uptake of labile organic carbon, $C_{L}$, by $\mathrm{PH}$ can occur at extremely low concentrations when $\varepsilon_{P H}$ is close to zero, but small $\varepsilon_{P H}$ values means very little biomass is produced as a results. This is an interesting result, as light energy is being used to scavenge organic carbon at low concentrations, which contributes to the low labile organic carbon observed 


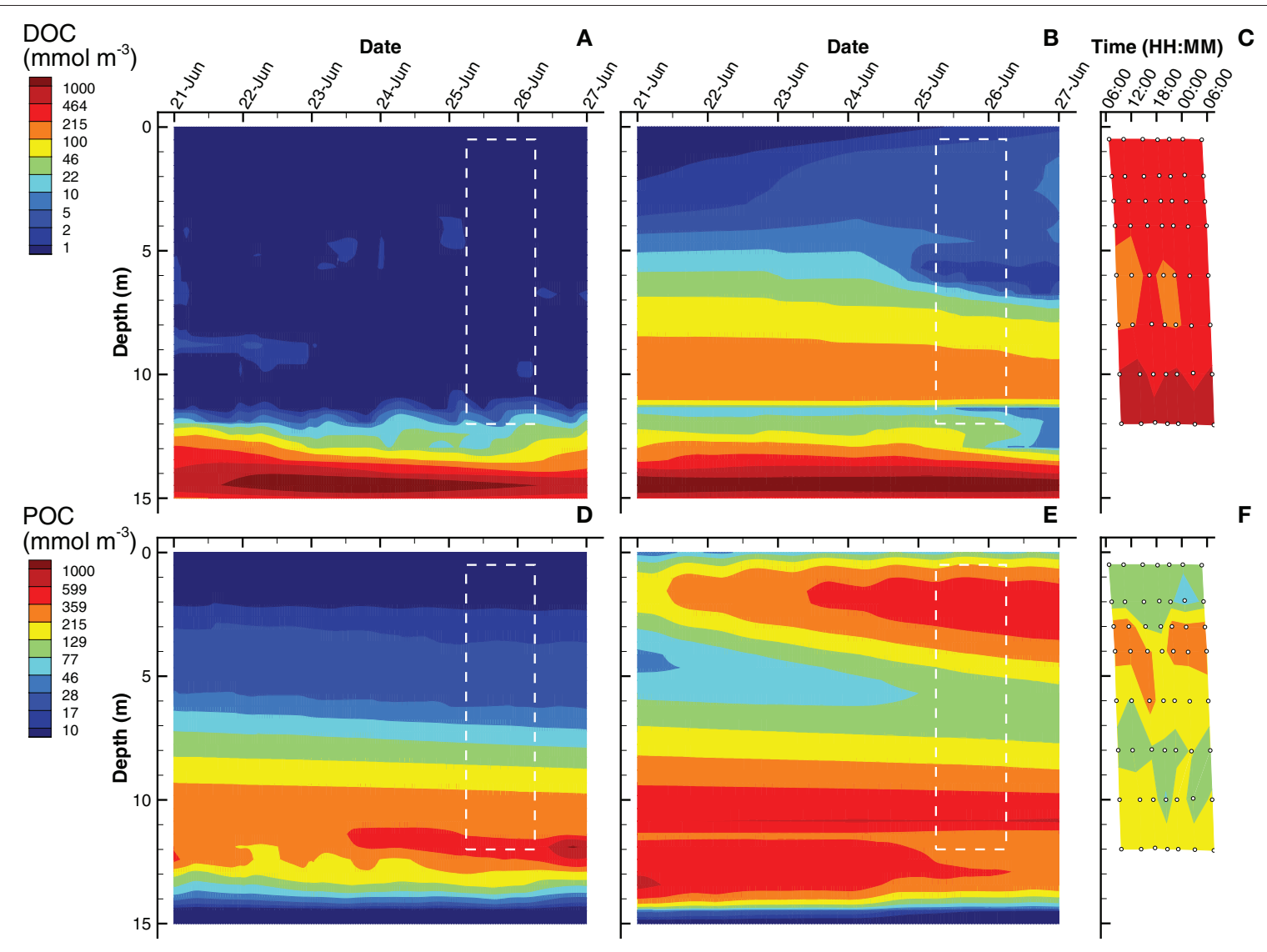

FIGURE 6 | Contour plots of dissolved organic carbon (DOC) (A-C) and particulate organic carbon (POC) (D-F) concentrations for SIO and LIO simulations (left and center columns, respectively) and Siders Pond observations (right column). See caption to Figure $\mathbf{3}$ for other details.

in the SIO simulation (Figure 6A). Furthermore, the high entropy production from reaction, $\dot{\sigma}_{R}$ (Figure 7B), is almost entirely due to $\mathrm{PH}$. One of the reasons both green sulfur bacteria and photoheterotrophs are more active in the SIO versus LIO simulations is that light is not being intercepted by phytoplankton like it is in the LIO simulation (Figure 8A vs. Figure 8F).

Bacterial densities are similar in the two simulations (Figures S4a,d), but there is significantly higher growth rate by bacteria in the LIO simulation between 4 and $10 \mathrm{~m}$ (Figures S4b,e). Both simulations allocate almost all of detrital carbon decomposition, $r_{2, B a c}$, below $13 \mathrm{~m}$ (Figures S5c,f), but the SIO simulation also allocates biomass to detrital carbon decomposition sporadically throughout the water column to produce $C_{L}$ (Figure $\mathbf{S 4 c}$ ). The anaerobic, sulfate reducing bacteria function similarly as bacteria, but operate in the anaerobic portion of the water column (Figures S6, S7). Like bacteria (Bac), the sulfate reducing bacteria (SRB) allocate biomass to detrital carbon decomposition, $r_{2, S R B}$, below $13 \mathrm{~m}$ in both SIO and LIO simulations (Figures S7c,f) and sporadically throughout the water column in the SIO simulation (Figure S7c). Overall, bacteria and SRB function in a complementary mode across the aerobic and anaerobic portions of the water column. Similar to phytoplankton, the control variables for both $\mathcal{E}_{B a c}$ and $\mathcal{E}_{S R B}$ show more rapid (bang-bang) control in the SIO compared to the LIO simulation (Figures S5, S7). The third bacterial group, sulfide oxidizing bacteria, $\mathcal{S}_{S O x}$, are largely unimportant in either of the 6 day simulations.

Another significant difference between the SIO and LIO simulations is a greater importance of predation, $\mathfrak{Z}_{G z}$, in the SIO solution (Figure 11). Because predation is abstracted in the MEP model, it represents all predation mechanisms, including protists, predatory bacteria, viruses, and cannibalism. In addition to dissipating chemical potential stored as biomass, predation serves a more important task of recycling nutrients from biomass that are allocated to metabolic functions that are not needed under prevailing conditions. The SIO and LIO simulations show that the concentration of $\mathscr{S}_{G z}$ is more than 4 times higher in SIO than LIO solutions, and $\mathfrak{S}_{G z}$ increases over time under the SIO objective. The primary prey items in the SIO solution are $\mathfrak{S}_{G z}$ (i.e., cannibalism), $\mathcal{B}_{B a c}$ and $\boldsymbol{Z}_{P H}$ (Figures 11B-D), while only ${ }_{B a c}$ predation is of significance in the LIO solution (Figure 11G). Closer inspection of Figures 11B,C reveals that predation occurs predominately at night, which is a result of temporal changes in the partitioning control variables, $\Omega_{i, G z}$, 

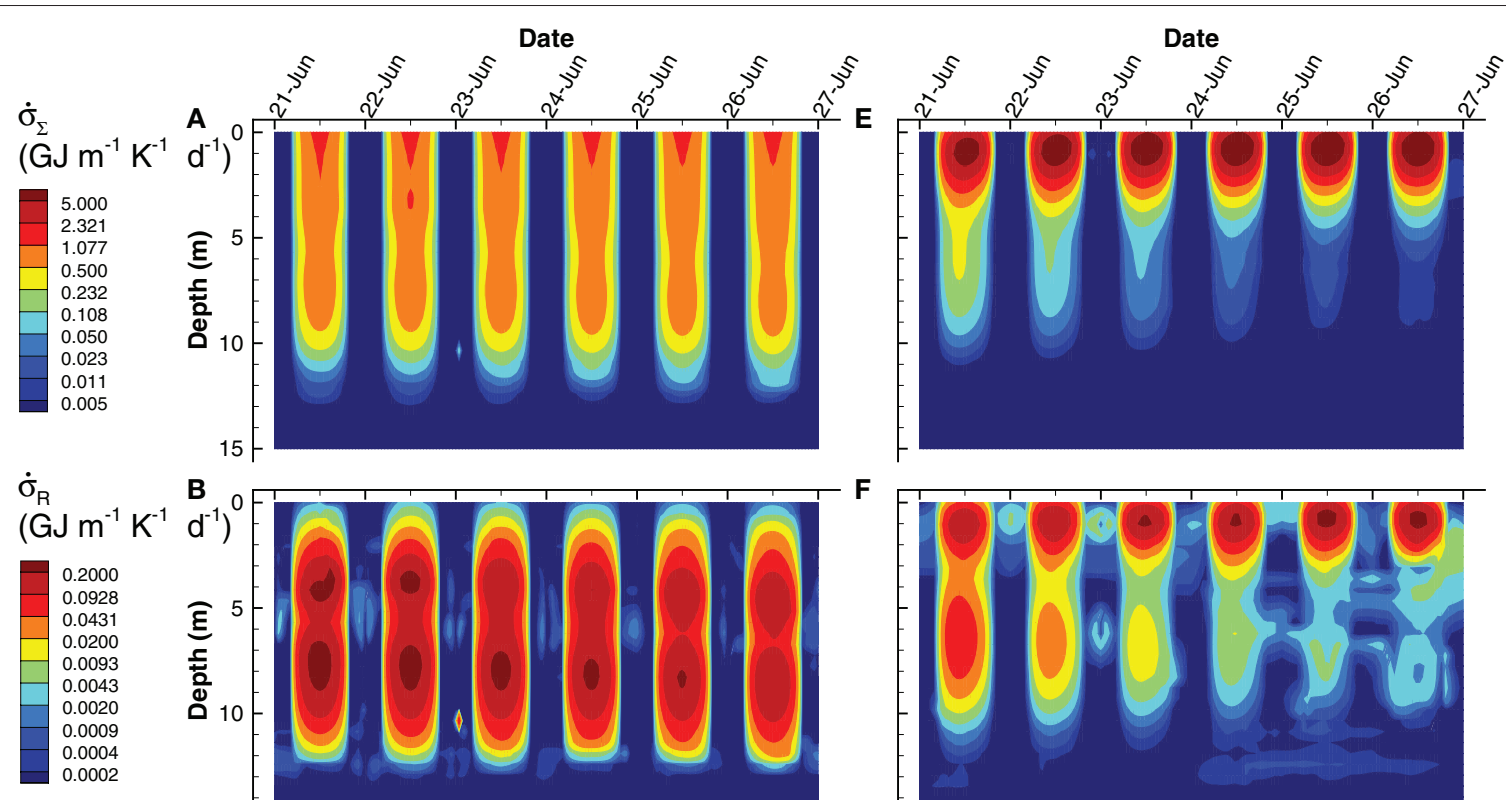

$$
\text { B }
$$

$\left.\mathrm{d}^{-1}\right)^{0}$
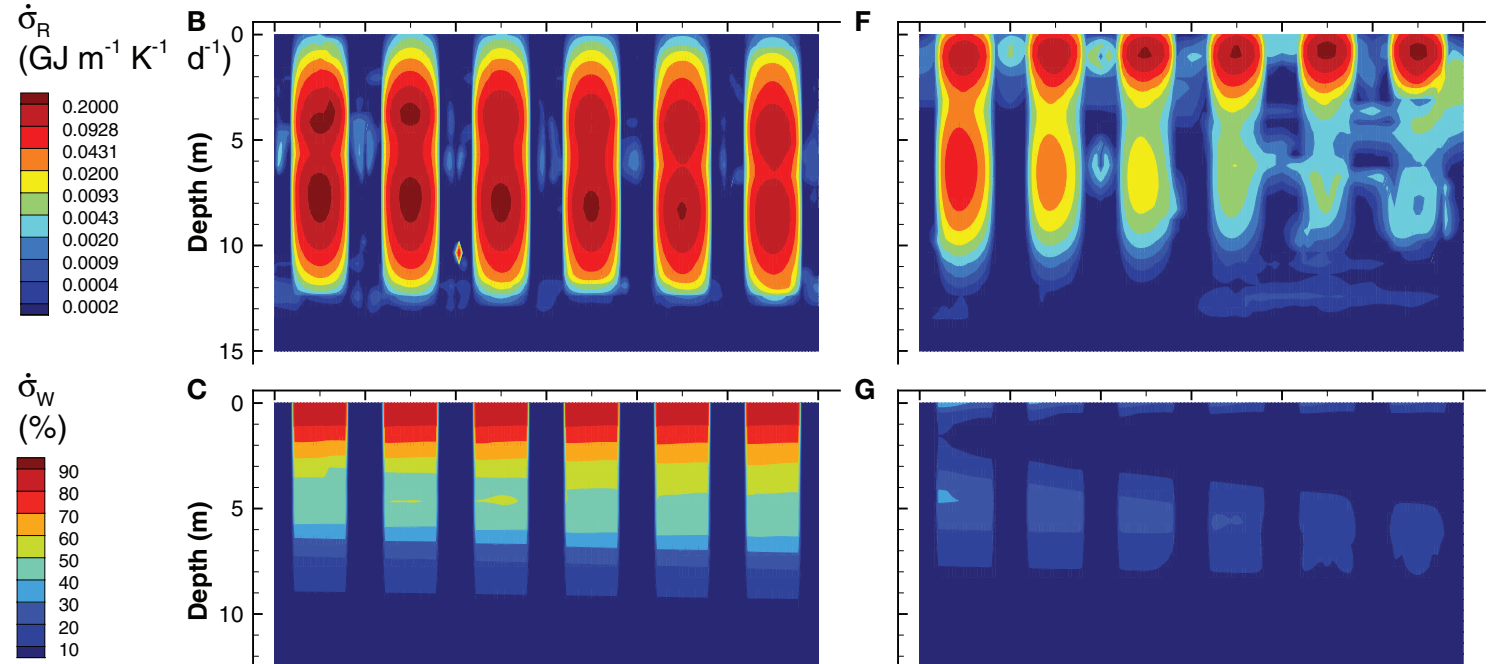

C
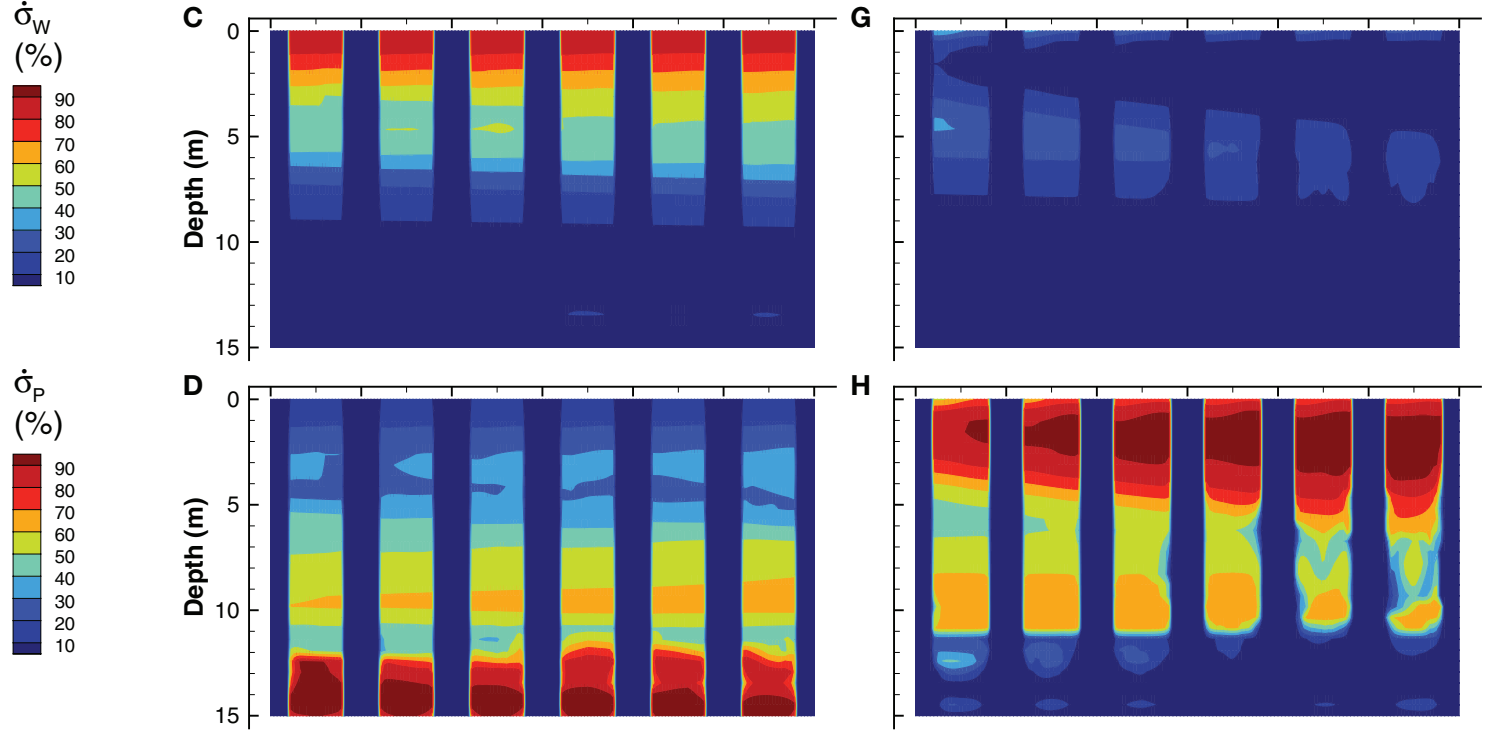

FIGURE 7 | Contour plots of simulated total entropy production, $\dot{\sigma}_{\Sigma}$ (Eq. (S178)) (A,E), entropy production from reactions, $\dot{\sigma}_{R}$ [Equation (S178)] (B,F), and entropy production from light absorption by water, $\dot{\sigma}_{W}(t, z)$ [Equation $\left.(\mathbf{S} 176)\right] \mathbf{( C , G )}$ and particles, $\dot{\sigma}_{P}$ [Equation (S177)] (D,H) for the SIO (left column) and LIO (right column) simulations. Entropy production from light dissipation by water and particles are shown as a percentage of total entropy production.

rather than prey concentration (not shown). High concentration of $\varepsilon_{G z}$ is found below $10 \mathrm{~m}$, but growth of grazers actually occurs between 4 and $7 \mathrm{~m}$, which indicates the high $\varepsilon_{G z}$ concentration below $10 \mathrm{~m}$ is due to sinking and accumulation. Accumulation of biomass in the deep, anaerobic, portion of the water column becomes food for anaerobic predators, $\dot{z}_{A G z}$, which are important in both SIO and LIO simulations, but are slightly more active in the LIO simulation (Figure S8).

An interesting result that derives from the focus on dissipating energy potentials rather than on growing organisms is the importance of chemotrophs on dissipating electromagnetic potential. For instance, aerobic organoheterotrophic bacteria, $\mathcal{G}_{B a c}$, are well understood as dissipaters of chemical potential, as they typically respire significant amounts of organic carbon (i.e., $\varepsilon_{B a c}<0.5$ ). In both the SIO and LIO simulations, however, far more free energy is dissipated by passive light absorption than it is by respiration (Figure 12), although the difference is more striking in the SIO simulation (Figure 12A vs. Figure 12B). Some prokaryotes in nature harness this abundant light energy via expression of proteorhodopsin (Béjà et al., 2000), which is perhaps more widespread than currently appreciated (Dubinsky et al., 2017). 


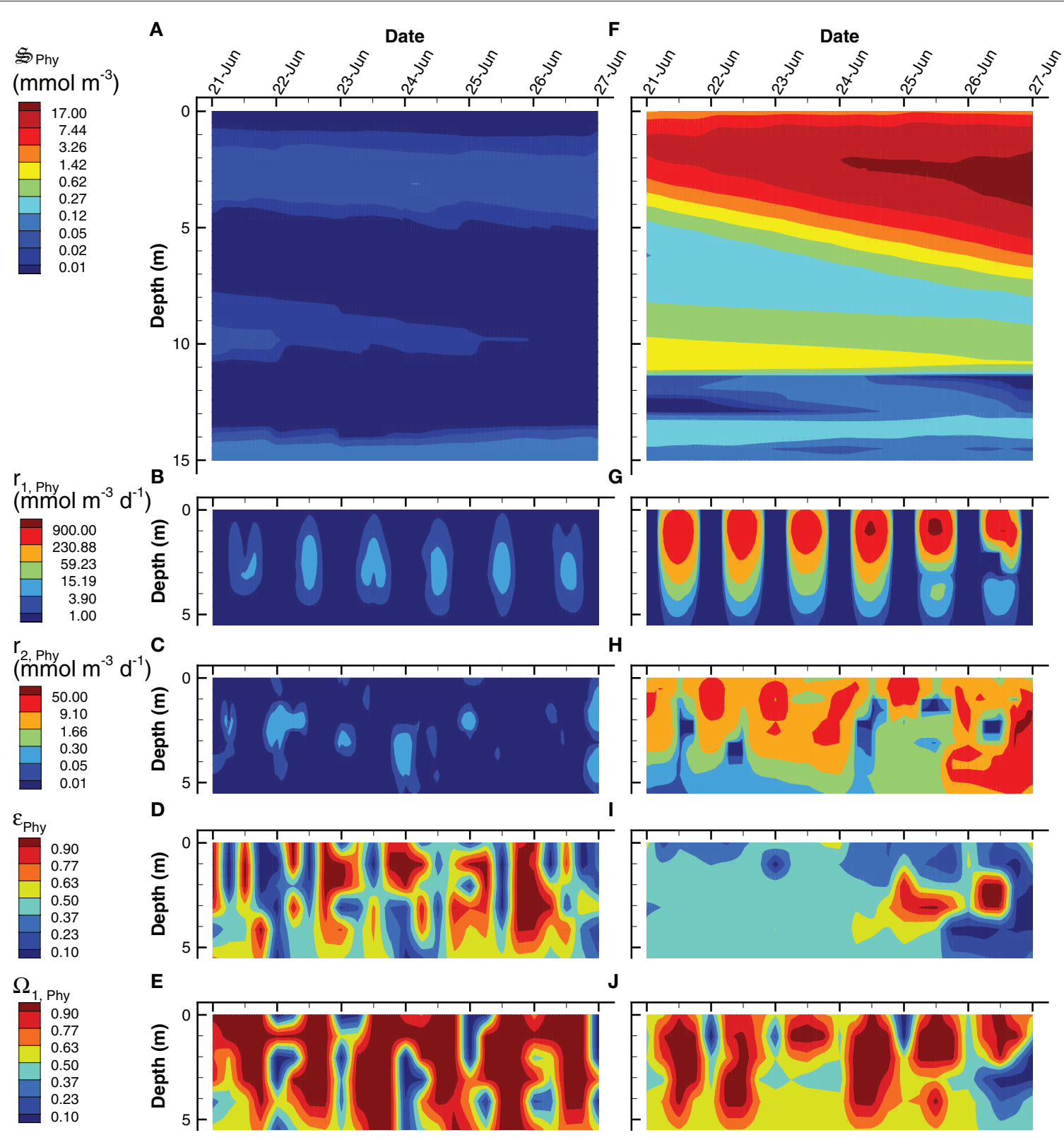

FIGURE 8 | Contour plots of phytoplankton concentration, [ $\boldsymbol{Z}_{\text {Phy }}$ ] (A,F), rates for the two associated reactions, $r_{1, P h y}$ (B,G) and, $r_{2, \text { Phy }}$ (C,H) and two optimal control variables, $\varepsilon_{\text {Phy }}(\mathbf{D}, \mathbf{I})$, and $\Omega_{1, \text { Phy }}(\mathbf{E}, \mathbf{J})$ for the SIO $(\mathbf{A}-\mathbf{E})$ and $\mathrm{LIO}(\mathbf{F}-\mathbf{J})$ simulations. Note, reaction rates and control variables are only plotted for the top $5 \mathrm{~m}$ of the water column where the processes are significant.

\section{DISCUSSION}

The two primary objectives of this study were to demonstrate that (1) a model based on free energy dissipation can reasonably describe microbial community organization and function with relatively few parameters and (2) that microbial systems operate collectively over characteristic timescales that are likely longer than what common wisdom would suggest. The secondary objectives were to demonstrate how the model can be used in systems with spatial dimensions and to extend the approach to include phototrophs. While improvements could be made with explicit data assimilation (Edwards et al., 2015), the MEP model did a reasonable job at simulating biogeochemistry in Siders Pond with few adjustable parameters, and the better fit of the long interval optimization (LIO) simulation to 6 out of 9 observations indicates that the microbial community has evolved to function over time scales that are longer than 0.25 days (Table 3). The MEP optimization approach removed approximately 89 parameters that would have had to be tuned if a conventional model had been used (Ward et al., 2010). Perhaps the most 


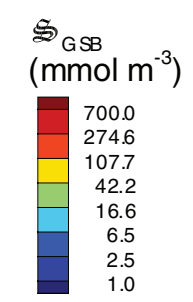

(mmol m $\left.{ }^{-3} \mathrm{~d}^{-1}\right)$

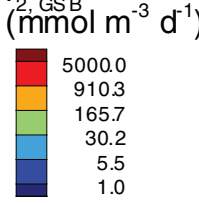

$\varepsilon_{\mathrm{GSB}}$

0.90

0.77

0.63

0.50

0.37

0.23

0.10

A

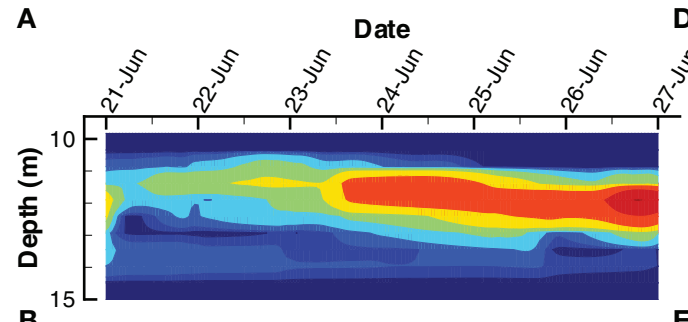

B

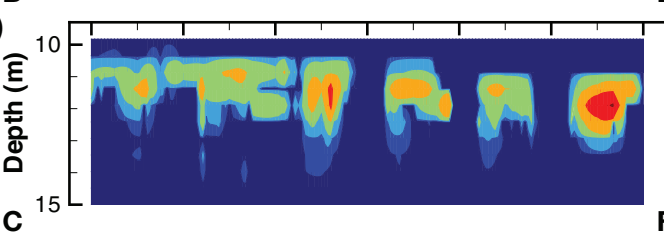

E
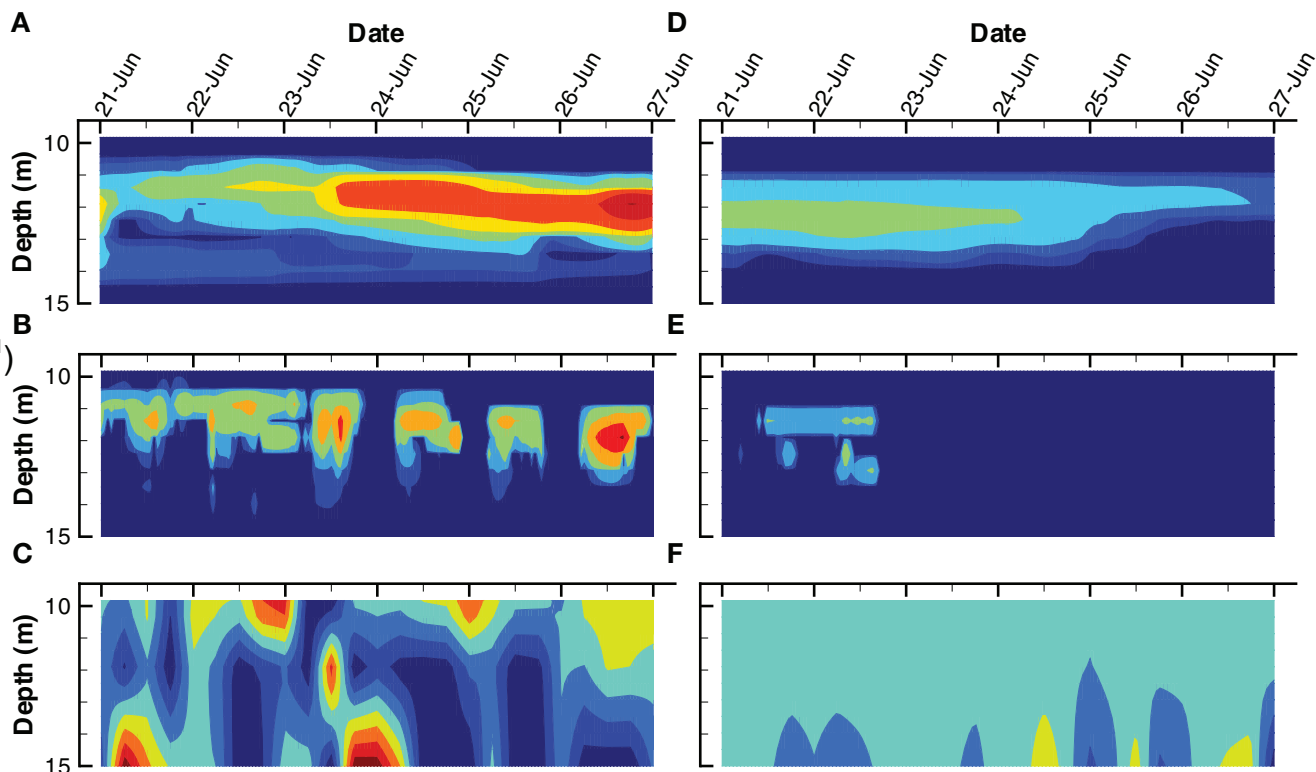

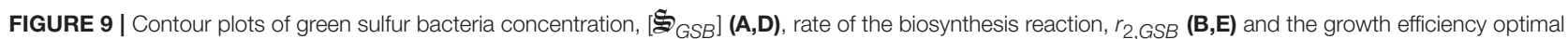
control variable, $\varepsilon_{G S B}(\mathbf{C}, \mathbf{F})$ for the SIO (A-C) and LIO (D-F) simulations. Note, variables are only plotted for $10 \mathrm{~m}$ to $15 \mathrm{~m}$ where the GSB are active.

useful aspect is that MEP provides a different perspective to view biology (Skene, 2017). For the Siders Pond model, the perspective focused our attention on how microbial functional activity changes with the length of the entropy integration interval, $\Delta t$.

Temporal strategies, such as circadian clocks (Wolf and Arkin, 2003), anticipatory control (Mitchell et al., 2009; Katz and Springer, 2016), energy and resource storage (Schulz et al., 1999; Grover, 2011), and dormancy (Lewis, 2010) are hallmarks of biology, yet they are often not given much consideration when theory and models are developed for understanding biogeochemistry, even though temporal strategies have also been observed in microbial communities (Ottesen et al., 2014). Here our model results indicate that different organizational timescales can dramatically impact biogeochemistry and how microbial communities function. For instance, the SIO simulation does not invest resources in phytoplankton growth, because over the short 0.25 day optimization, water dissipates more electromagnetic potential than a small increase in phytoplankton biomass over the short interval. Instead, the SIO solution allocates resources to growth of green sulfur bacteria (GSB) and photoheterotrophs $(\mathrm{PH})$ deeper in the water column to dissipate light not adsorbed by water in the surface. The SIO solution also places more resources on decomposing refractory carbon, but also on respiring the liberated labile carbon. Grazing rates, especially under aerobic conditions, are higher in the SIO simulations as well. These types of resource allocations in the SIO solution appear more consistent with $\mathrm{R}^{*}$ or resource-ratio theory (Tilman, 1982) and r-selection (Pianka, 1970; Fierer et al., 2007); that is, emphasis on fast growth. On the contrary, the LIO solution appears more similar to K-selection where resources are invested for longer term outcomes. These differences are also evident in the control variables. In the SIO simulations, the control variables show rapid bang-bang control fluctuations as resources vary (Figure 8D), while the LIO solution produces more gradual changes in control variables (Figure 8I). A microbial community that implements temporal strategies should outcompete a community that lacks temporal strategies, because long-term strategies result in greater acquisition and utilization of food resources under non steady-state conditions than short-term strategies (Cole et al., 2015), which is evident by the $71 \%$ greater entropy production over the 6 day simulations using LIO versus SIO (36.5 GJ K ${ }^{-1}$ vs. $21.3 \mathrm{GJ} \mathrm{K}^{-1}$ ).

One of the main questions that arise in applying MEP is what is the appropriate timescale over which biology organizes? That is, in the current implementation of the model, what is an appropriate value for $\Delta t$ used in the optimal control problem? In this study two values were explored, 0.25 days for the SIO and 3 days for the LIO. These choices were based on the observation time scale, where 0.25 day is "short" compared to 1 day, and 3 days is "long" in comparison to 1 day. Our results indicate that the SIO solution did not match observations or expectations as well as the LIO solution (Table 3). Comparing MEP model output to observations for differing values of $\Delta t$ is one means to explore this fundamental property of ecosystems. But is a $3 \mathrm{~d}$ optimization window sufficient? It seems the appropriate MEP time scales do not depend on just the characteristic time scales of organisms, because our study on periodically forced methanotroph communities showed that the communities were well adapted to 20 day cyclic inputs of energy, even though the characteristic turnover time of bacteria is closer to hours (Vallino et al., 2014; Fernandez-Gonzalez et al., 2016). We know that terrestrial systems function on long timescales, at least on the order of the four seasons, but their time scales are likely much 

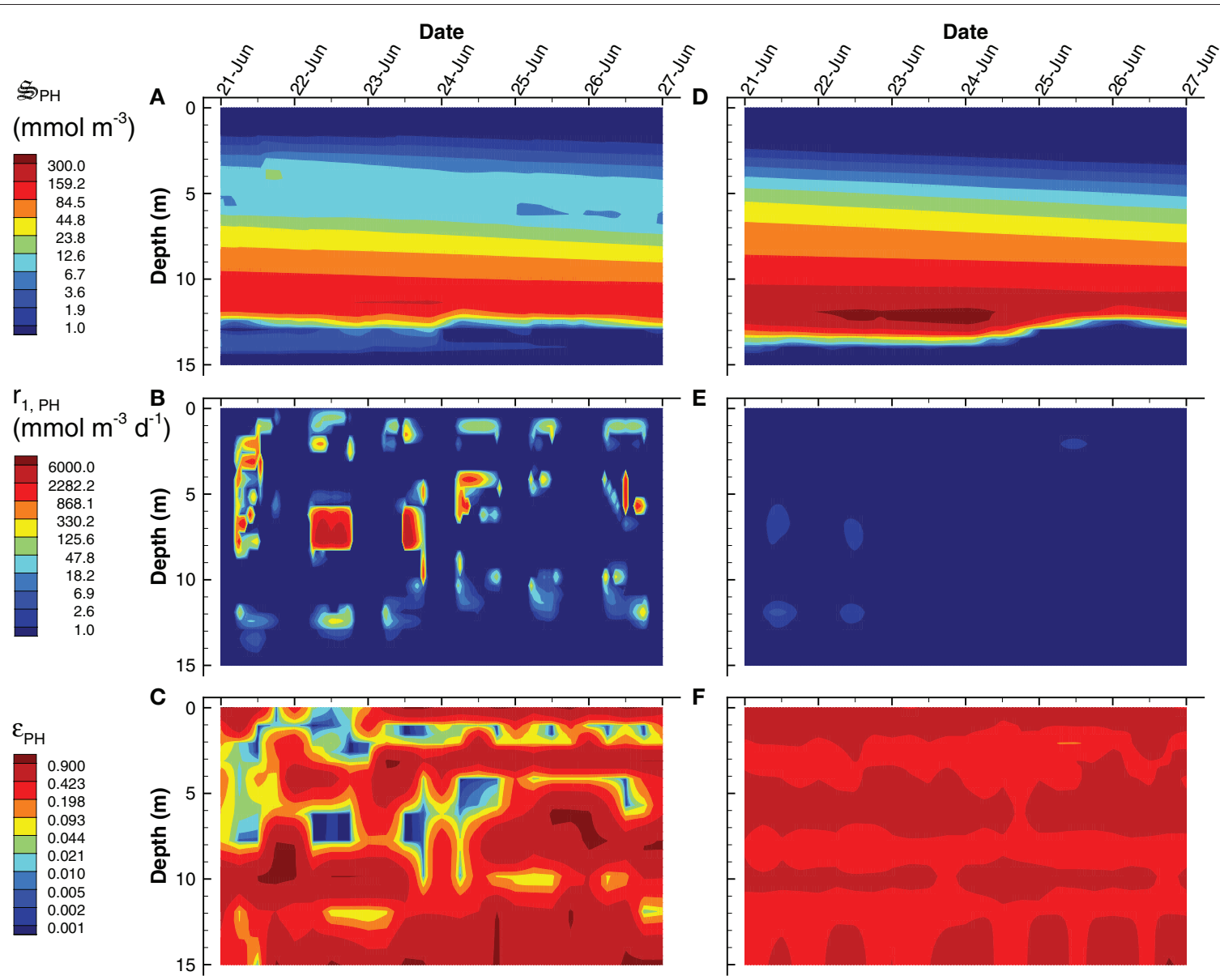

FIGURE 10 | Contour plots of photoheterotroph concentration, [ $\tilde{S}_{P H}$ ] (A,D), rate of the carbon fixation reaction, $r_{1, P H}(\mathbf{B}, \mathbf{E})$ and the growth efficiency optimal control variable, $\varepsilon_{P H}(\mathbf{C}, \mathbf{F})$ for the $\mathrm{SIO}(\mathbf{A}-\mathbf{C})$ and $\mathrm{LIO}$ (D-F) simulations. Note, contours for $\varepsilon_{P H}$ were selected to emphasize $\varepsilon_{P H}$ values near zero.

longer given that individual trees can live hundreds of years, and forest succession takes longer than that (Odum, 1969; Finegan, 1984). At this time, we do not have an answer to the question regarding an appropriate optimization time scale for microbial communities, but it is likely related to the time scales over which biological predictions, acquired by evolution, can be reliably made, such as the sun will return tomorrow, or winter is coming. Predicting the future has obvious evolutionary advantages, but it also results in greater dissipation of free energy and entropy production, as evident by the higher entropy produced by the LIO solution. We believe that determining the temporal scales over which microbial communities operate will be important for developing predictive biogeochemistry models, but space scales are also import.

Strategies that coordinate function over space also lead to greater free energy dissipation (Vallino, 2011). Some examples of such coordination include quorum sensing (Goo et al., 2012; Hmelo, 2017) and associated quorum policing (Whiteley et al., 2017), long-range metabolic signaling (Liu et al., 2015), stigmergy (Gloag et al., 2013), horizontal gene transfer (Treangen and Rocha, 2011), cables and nanowires (Reguera et al., 2005; Schauer et al., 2014), cross-feeding (Estrela et al., 2012; Rakoff-Nahoum et al., 2016), chemotaxis (Stocker and Seymour, 2012), vertical migration (Inoue and Iseri, 2012) and other types infochemical exchange (Moran, 2015). Our original intent was to compare local versus global MEP optimization, but global optimization in the Siders Pond model did not produce biologically relevant results due to the speed at which electromagnetic potential is dissipated abiotically. Because water and sediments rapidly absorb light, any water column of sufficient depth will dissipate all incoming radiation as entropy regardless of the presence of organisms, so an infinite number of solutions exist that all produce the same global entropy production. However, maximizing local entropy production at discrete depths, as was conducted in this study, does select for a unique solution, which our results show is biologically relevant. Our previous study with purely chemical reactions showed that global entropy production results in greater chemical potential destruction (Vallino, 2011). This study indicates that if abiotic processes can destroy an energy potential faster than biotic ones, then local MEP optimization will be the preferred solution. Global maximization of entropy production is more likely to be found in 


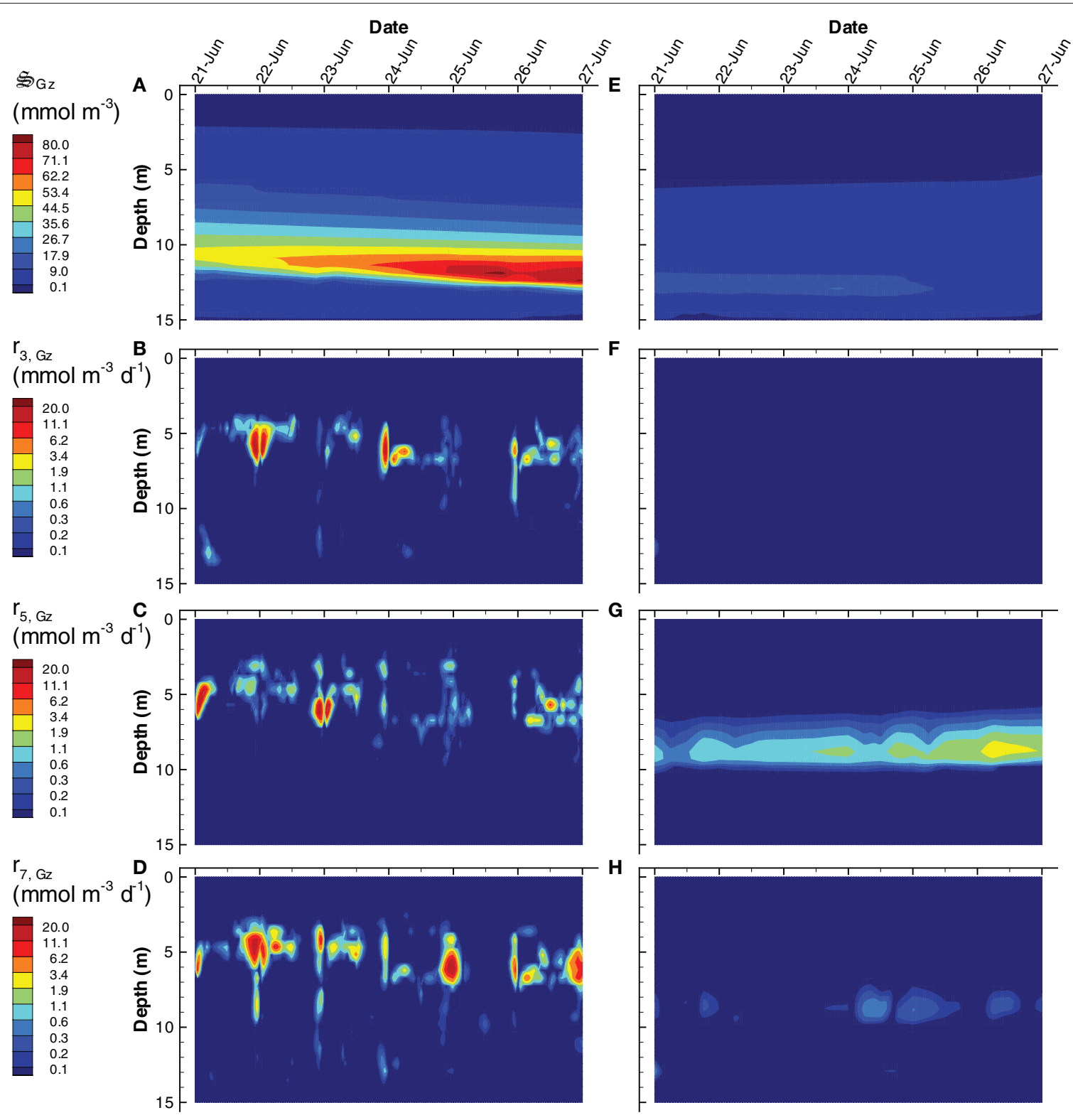

FIGURE 11 | Contour plots of grazer concentration, $\left[\tilde{g}_{G z}\right]$ (A,E) and rates of predation on, grazers, $r_{3, G z}$ (B,F), bacteria, $r_{5, G z}$ (C,G), and photoheterotrophs, $r_{7, G z}$ $(\mathbf{D}, \mathrm{H})$ for the $\mathrm{SIO}$ (A-D) and LIO (D-H) simulations.

systems where energy potentials are stable with respect to abiotic decay, such as chemical potentials. However, it seems possible that both local and global optimization could be operating simultaneously in systems given that both light and chemical potentials often exist, so further studies are needed.

Other areas that could improve the MEP modeling approach are as follows. Our metabolic network (Figure 1) was largely based on prior knowledge about Siders Pond biogeochemistry, but condensing genome-scale models may also be a means to construct more realistic whole community metabolic networks from genomic surveys (Hanson et al., 2014; Hanemaaijer et al., 2015), and exometabolomics could be used to identify metabolite nodes in the distributed metabolic network that are widely exchanged between functional groups (Klitgord and Segre, 2010; Baran et al., 2015; Fiore et al., 2015; Ponomarova and Patil, 2015). Also, our current approach relies on non-linear optimal control to locate MEP solutions, but this is a computationally intensive problem, and falls under the class of problems known as control of partial differential equations (Coron, 2007). Building on expertise from that field could reduce computation requirements, especially for problems involving two or three spatial dimensions, but it might be possible to avoid the formal optimization problem altogether. One possibility would be to use Darwinian inspired trait-based modeling approaches (Follows et al., 2007; Coles et al., 

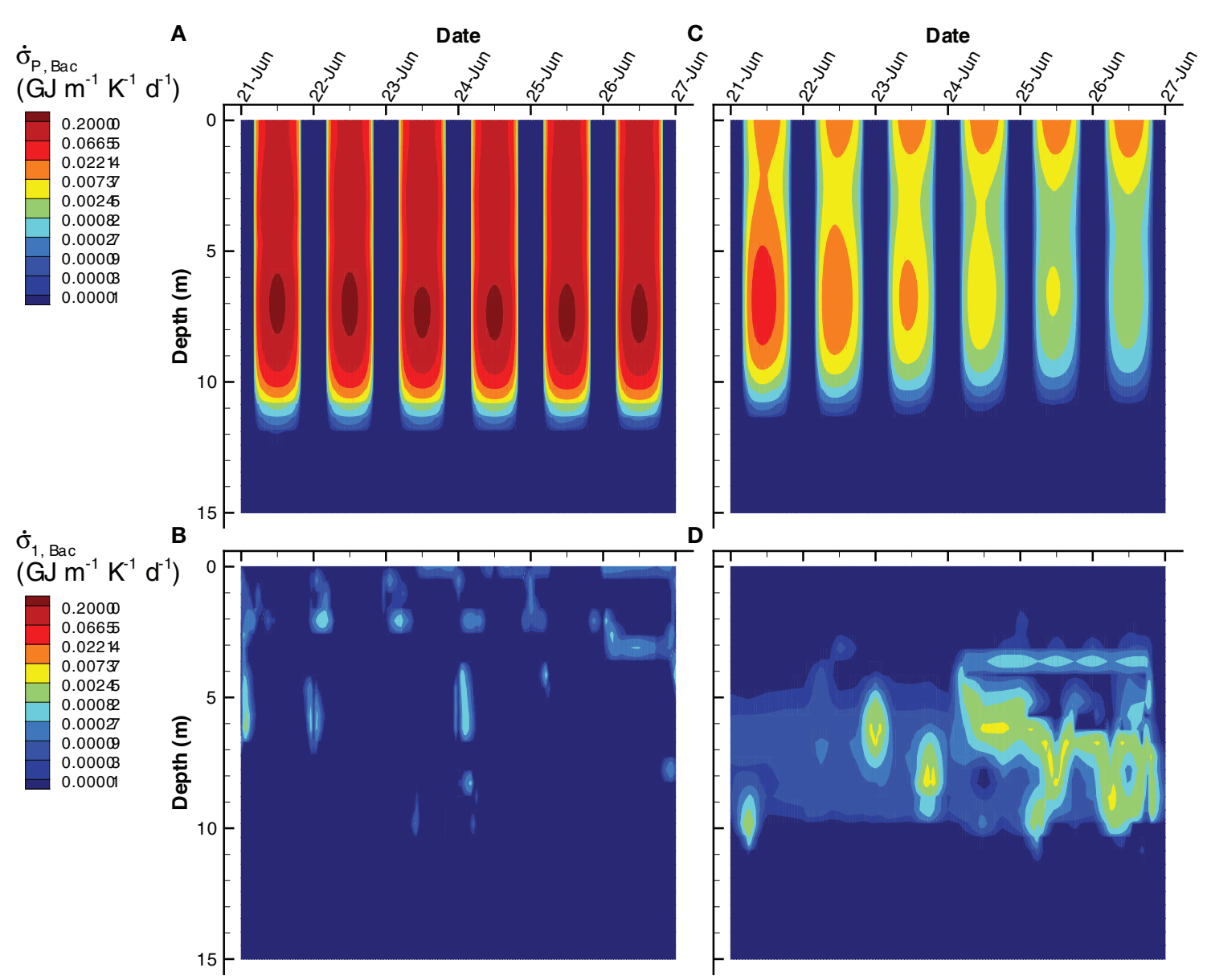

D
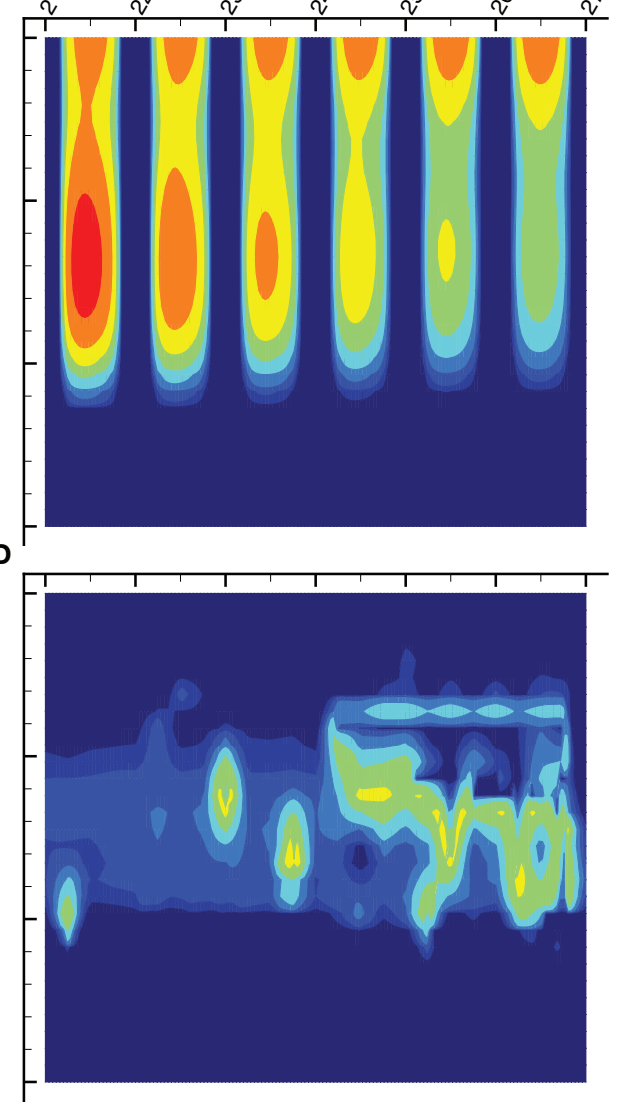

FIGURE 12 | Contour plots of entropy production by bacteria associated with light absorption by bacterial biomass, $\dot{\sigma}_{P, B a c}$ (A,C) and growth of bacteria, $r_{1, B a c}$, on organic carbon, $\dot{\sigma}_{1, B a c}$, Equation (S94) (B,D) for the SIO (A,B) and LIO (C,D) simulations.

2017), which is how biology actually solves the MEP problem. On the other hand, MEP could be useful for developing trait models that improve entropy production over time and space, such as traits that include resource storage, time delays (i.e., dormancy), migration across fronts and boundaries to acquire resources, clocks and oscillators, distribution and packaging of metabolic function, predation, remineralization, and other regulatory motifs (Wolf and Arkin, 2003). By placing emphasis on the mechanisms of how energy potentials are destroyed over time and space, rather than on the peculiarities of how organisms grow and survive, can lead to new insights that can improve our understanding of biogeochemistry and model predictions thereof.

\section{CONCLUSIONS}

Our results demonstrate that models based on MEP can reasonably simulate how microbial communities organize and function in Siders Pond over time and space while using a minimum of adjustable parameters. The improved qualitative and quantitative agreement between model predictions and observations using long ( 3 day, LIO) versus short (0.25 day, SIO) interval optimization supports the hypothesis that biological systems maximize entropy production over long time scales. The modeling presented here extends the MEP approach to include an explicit spatial dimension, and new metabolic reactions were introduced to model phototrophs and entropy production associated with the destruction of electromagnetic potential. By considering the dissipation of both chemical and electromagnetic potentials, the MEP model shows that heterotrophs, such as bacteria, dissipate far more free energy in the photic zone by passive light absorption than by chemical respiration. Short interval optimization results in higher grazing rates and turnover of organic carbon, as well as rapid (bang-bang) changes in the reaction control variables, while long interval optimization supports higher phytoplankton growth and standing stocks near the surface of the pond. We also found that maximization of local entropy production, as opposed to global entropy production, must be used for energy potentials that are quickly dissipated by abiotic processes, such as light absorption by water and particles. Taken together, results validate our general conjecture 
that biological systems evolve and organize to maximize entropy production over the greatest possible spatial and temporal scales, while abiotic processes maximize instantaneous and local entropy production.

\section{AUTHOR CONTRIBUTIONS}

Both JV and JH contributed equally to project concepts and design, and both conducted the $24 \mathrm{~h}$ sampling of Siders Pond. Preliminary results from metatranscriptomics and metagenomics from $\mathrm{JH}$ were used to improve development of the metabolic network. JV developed the model and wrote first draft of the manuscript with editing and inputs during the process from JH. Both authors contributed to manuscript revision, read and approved the submitted version.

\section{FUNDING}

Primary funding for this project was from NSF GG grant EAR1451356 to $\mathrm{JV}$ and $\mathrm{JH}$, with additional support from Gordon and Betty Moore Foundation grant GBMF 3297. JV also received support from NSF Grants OCE-1637630 and OCE-1558710 and Simons Foundation grant 549941. The NSF Center for Dark Energy Biosphere Investigations (C-DEBI; OCE-0939564) also

\section{REFERENCES}

Alberty, R. A. (2003). Thermodynamics of Biochemical Reactions. Hoboken, NJ: Wiley and Sons.

Algar, C. K., and Vallino, J. J. (2014). Predicting microbial nitrate reduction pathways in coastal sediments. Aquat. Microb. Ecol. 71, 223-238. doi: $10.3354 /$ ame01678

Baran, R., Brodie, E. L., Mayberry-Lewis, J., Hummel, E., Da Rocha, U. N., Chakraborty, R., et al. (2015). Exometabolite niche partitioning among sympatric soil bacteria. Nat. Commun. 6:8289. doi: 10.1038/ ncomms 9289

Battley, E. H., Putnam, R. L., and Boerio-Goates, J. (1997). Heat capacity measurements from 10 to $300 \mathrm{~K}$ and derived thermodynamic functions of lyophilized cells of Saccharomyces cerevisiae including the absolute entropy and the entropy of formation at $298.15 \mathrm{~K}$. Thermochim. Acta 298, 37-46. doi: 10.1016/S0040-6031(97)00108-1

Béjà, O., Aravind, L., Koonin, E. V., Suzuki, M. T., Hadd, A., Nguyen, L. P., et al. (2000). Bacterial rhodopsin: evidence for a new type of phototrophy in the sea. Science 289, 1902-1906. doi: 10.1126/science.289.54 86.1902

Blumenfeld, L. A. (1981). Problems of Biological Physics. Berlin: Springer-Verlag.

Brock, T. D. (1981). Calculating solar radiation for ecological studies. Ecol. Model. 14, 1-19. doi: 10.1016/0304-3800(81)90011-9

Candau, Y. (2003). On the exergy of radiation. Solar Energy 75, 241-247. doi: 10.1016/j.solener.2003.07.012

Caraco, N. (1986). Phosphorus, Iron, and Carbon Cycling in a Salt Stratified Coastal Pond. Ph.D. thesis, Boston University.

Caraco, N., and Puccoon, A. H. (1986). The measurement of bacterial chlorophyll and algalchlorophyll a in natural waters. Limnol. Oceanogr. 31, 889-893. doi: 10.4319/lo.1986.31.4.0889

Caraco, N., Tamse, A., Boutros, O., and Valiela, I. (1987). Nutrient limitation of phytoplankton growth in brackish coastal ponds. Can. J. Fish. Aquat. Sci. 44, 473-476. doi: 10.1139/f87-056

Chapman, E. J., Childers, D. L., and Vallino, J. J. (2016). How the Second Law of Thermodynamics has informed ecosystem ecology through its history. BioScience 66, 27-39. doi: 10.1093/biosci/biv166 supported the participation of $\mathrm{JH}$. This is C-DEBI contribution number 441 .

\section{ACKNOWLEDGMENTS}

We thank Petra Byl for assistance in field work preparation and sampling of Siders Pond, as well as insightful conversations about the project. We also thank Jane Tucker for dissolved inorganic carbon analyses, Suzanne Thomas for hydrogen sulfide analyses, Sam Kelsey for dissolved organic carbon analyses, Kate Morkeski for sulfate, phosphate and particulate organic carbon analyses, and Rich McHorney, Leslie Murphy, Emily Reddington, and Gretta Serres for assistance with Siders Pond sampling logistics. We also thank the Semester in Environmental Science Program at MBL for use of their Hydrolab and Jon Boat used for sampling, and a special thank you to Tom Gregg who allowed us to access Siders Pond through his property as well as for providing logistical support.

\section{SUPPLEMENTARY MATERIAL}

The Supplementary Material for this article can be found online at: https://www.frontiersin.org/articles/10.3389/fenvs. 2018.00100/full\#supplementary-material

Cole, J. A., Kohler, L., Hedhli, J., and Luthey-Schulten, Z. (2015). Spatially-resolved metabolic cooperativity within dense bacterial colonies. BMC Syst. Biol. 9:15. doi: 10.1186/s12918-015-0155-1

Coles, V. J., Stukel, M. R., Brooks, M. T., Burd, A., Crump, B. C., Moran, M. A., et al. (2017). Ocean biogeochemistry modeled with emergent trait-based genomics. Science 358, 1149-1154. doi: 10.1126/science.aan5712

Coron, J.-M. (2007). Control and Nonlinearity. Providence, RI: American Mathematical Society.

Dewar, R. (2003). Information theory explanation of the fluctuation theorem, maximum entropy production and self-organized criticality in non-equilibrium stationary states. J. Phys. A Math. Gen. 36, 631-641. doi: $10.1088 / 0305-4470 / 36 / 3 / 303$

Dewar, R., Lineweaver, C., Niven, R., and Regenauer-Lieb, K. (2014a). "Beyond the Second Law: an overview," in Beyond the Second Law, eds R. C. Dewar, C. H. Lineweaver, R. K. Niven and K. Regenauer-Lieb (Berlin; Heidelberg: Springer), 3-27.

Dewar, R. C., Lineweaver, C. H., Niven, R. K., and Regenauer-Lieb, K., (eds) (2014b). Beyond the Second Law: Entropy Production and Non-Equilibrium Systems. Berlin: Springer-Verlag.

Dubinsky, V., Haber, M., Burgsdorf, I., Saurav, K., Lehahn, Y., Malik, A., et al. (2017). Metagenomic analysis reveals unusually high incidence of proteorhodopsin genes in the ultraoligotrophic Eastern Mediterranean Sea. Environ. Microbiol. 19, 1077-1090. doi: 10.1111/1462-2920.13624

Edwards, C. A., Moore, A. M., Hoteit, I., and Cornuelle, B. D. (2015). Regional ocean data assimilation. Ann. Rev. Mar. Sci. 7, 21-42. doi: 10.1146/annurev-marine-010814-015821

Estrela, S., Trisos, C. H., and Brown, S. P. (2012). From metabolism to ecology: cross-feeding interactions shape the balance between polymicrobial conflict and mutualism. Am. Nat. 180, 566-576. doi: 10.1086/6 67887

Fasham, M. J. R., Ducklow, H. W., and McKelvie, S. M. (1990). A nitrogen-based model of plankton dynamics in the ocean mixed layer. J. Mar. Res. 48, 591-639. doi: $10.1357 / 002224090784984678$

Fernandez, A., Huang, S., Seston, S., Xing, J., Hickey, R., Criddle, C., et al. (1999). How stable is stable? Function versus community composition. Appl. Environ. Microbiol. 65, 3697-3704. 
Fernandez-Gonzalez, N., Huber, J. A., and Vallino, J. J. (2016). Microbial communities are well adapted to disturbances in energy input. mSystems 1:e00117-16. doi: 10.1128/mSystems.00117-16

Fierer, N., Bradford, M. A., and Jackson, R. B. (2007). Toward an ecological classification of soil bacteria. Ecology 88, 1354-1364. doi: 10.1890/05-1839

Finegan, B. (1984). Forest succession. Nature 312, 109-114. doi: 10.1038/312109a0

Fiore, C. L., Longnecker, K., Kido Soule, M. C., and Kujawinski, E. B. (2015). Release of ecologically relevant metabolites by the cyanobacterium Synechococcus elongatus CCMP 1631. Environ. Microbiol. 17, 3949-3963. doi: 10.1111/1462-2920.12899

Fitzpatrick, J. J. (2009). Assessing skill of estuarine and coastal eutrophication models for water quality managers. J. Mar. Syst. 76, 195-211. doi: 10.1016/j.jmarsys.2008.05.018

Follows, M. J., Dutkiewicz, S., Grant, S., and Chisholm, S. W. (2007). Emergent biogeography of microbial communities in a model ocean. Science 315, 1843-1846. doi: 10.1126/science. 1138544

Friedrichs, M. A. M., Dusenberry, J. A., Anderson, L. A., Armstrong, R. A., Chai, F., Christian, J. R., et al. (2007). Assessment of skill and portability in regional marine biogeochemical models: role of multiple planktonic groups. J. Geophys. Res. 112:C08001. doi: 10.1029/2006JC003852

Gilboa-Garber, N. (1971). Direct spectrophotometric determination of inorganic sulfide in biological materials and in other complex mixtures. Anal. Biochem. 43, 129-133. doi: 10.1016/0003-2697(71)90116-3

Gloag, E. S., Javed, M. A., Wang, H., Gee, M. L., Wade, S. A., Turnbull, L., et al. (2013). Stigmergy: a key driver of self-organization in bacterial biofilms. Commun. Integr. Biol. 6:e27331. doi: 10.4161/cib.27331

Goldenfeld, N., and Woese, C. (2011). Life is physics: evolution as a collective phenomenon far from equilibrium. Annu. Rev. Cond. Matt. Phys. 2, 375-399. doi: 10.1146/annurev-conmatphys-062910-140509

Goo, E., Majerczyk, C. D., An, J. H., Chandler, J. R., Seo, Y. S., Ham, H., et al. (2012). Bacterial quorum sensing, cooperativity, and anticipation of stationary-phase stress. Proc. Natl. Acad. Sci. U.S.A. 109, 19775-19780. doi: $10.1073 /$ pnas.1218092109

Grover, J. P. (2011). Resource storage and competition with spatial and temporal variation in resource availability. Am. Nat. 178, E124-E148. doi: $10.1086 / 662163$

Hallam, S. J., and McCutcheon, J. P. (2015). Microbes don't play solitaire: how cooperation trumps isolation in the microbial world. Environ. Microbiol. Rep. 7, 26-28. doi: 10.1111/1758-2229.12248

Hanemaaijer, M., Röling, W. F., Olivier, B. G., Khandelwal, R. A., Teusink, B., and Bruggeman, F. J. (2015). Systems modeling approaches for microbial community studies: from metagenomics to inference of the community structure. Front. Microbiol. 6:213. doi: 10.3389/fmicb.2015.00213

Hanson, N. W., Konwar, K. M., Hawley, A. K., Altman, T., Karp, P. D., and Hallam, S. J. (2014). Metabolic pathways for the whole community. BMC Genomics 15:619. doi: 10.1186/1471-2164-15-619

Hmelo, L. R. (2017). Quorum sensing in marine microbial environments. Ann. Rev. Mar. Sci. 9, 257-281. doi: 10.1146/annurev-marine-010816-060656

Inoue, T., and Iseri, Y. (2012). Diel vertical migration and nutrient transport of the dinoflagellate Peridinium bipes F. occultatum in a thermally stratified reservoir. Water Sci. Technol. 66, 1212-1219. doi: 10.2166/wst.2012.302

Judson, O. P. (2017). The energy expansions of evolution. Nat. Ecol. Evol. 1:0138. doi: 10.1038/s41559-017-0138

Katz, Y., and Springer, M. (2016). Probabilistic adaptation in changing microbial environments. Peer J. 4:e2716. doi: 10.7717/peerj.2716

Kleidon, A., and Lorenz, R. D. (2005). Non-equilibrium Thermodynamics and the Production of Entropy. Berlin: Springer-Verlag.

Kleidon, A., Malhi, Y., and Cox, P. M. (2010). Maximum entropy production in environmental and ecological systems. Philos. Trans. R. Soc. B Biol. Sci. 365, 1297-1302. doi: 10.1098/rstb.2010.0018

Klitgord, N., and Segrè, D. (2010). Environments that induce synthetic microbial ecosystems. PLoS Comput. Biol. 6:e1001002. 1-17. doi: 10.1371/journal.pcbi.1001002

Konopka, A., Lindemann, S., and Fredrickson, J. (2015). Dynamics in microbial communities: unraveling mechanisms to identify principles. ISME J. 9, 1488-1495. doi: 10.1038/ismej.2014.251

La Rowe, D. E., Dale, A. W., Amend, J. P., and Van Cappellen, P. (2012). Thermodynamic limitations on microbially catalyzed reaction rates. Geochim. Cosmochim. Acta 90, 96-109. doi: 10.1016/j.gca.2012.0 5.011

Le Quere, C., Harrison, S. P., Colin Prentice, I., Buitenhuis, E. T., Aumont, O., Bopp, L., et al. (2005). Ecosystem dynamics based on plankton functional types for global ocean biogeochemistry models. Glob. Chang. Biol. 11, 2016-2040. doi: 10.1111/j.1365-2486.2005.1004.x

Lewis, K. (2010). Persister cells. Annu. Rev. Microbiol. 64, 357-372. doi: 10.1146/annurev.micro.112408.134306

Liu, J., Prindle, A., Humphries, J., Gabalda-Sagarra, M., Asally, M., and Lee, D. Y., et al. (2015). Metabolic co-dependence gives rise to collective oscillations within biofilms. Nature 523, 550-554. doi: 10.1038/nature14660

Locey, K. J., and Lennon, J. T. (2016). Scaling laws predict global microbial diversity. Philos. Trans. R. Soc. B Biol. Sci. 113, 5970-5975. doi: 10.1073/pnas.1521291113

Lorenz, R. (2003). Full steam ahead-probably. Science 299, 837-838. doi: $10.1126 /$ science. 1081280

Lotka, A. J. (1922). Contribution to the energetics of evolution. Philos. Trans. R. Soc. B Biol. Sci. 8, 147-151. doi: 10.1073/pnas.8.6.147

Louca, S., and Doebeli, M. (2016). Transient dynamics of competitive exclusion in microbial communities. Environ. Microbiol. 18, 1863-1874. doi: 10.1111/1462-2920.13058

Macedo, M. F., and Duarte, P. (2006). Phytoplankton production modelling in three marine ecosystems-static versus dynamic approach. Ecol. Modell. 190, 299-316. doi: 10.1016/j.ecolmodel.2005.05.012

Marino, N. A. C., Srivastava, D. S., and Farjalla, V. F. (2016). Predator kairomones change food web structure and function, regardless of cues from consumed prey. Oikos 125, 1017-1026. doi: 10.1111/oik.02664

Martyushev, L. M., and Seleznev, V. D. (2006). Maximum entropy production principle in physics, chemistry and biology. Phys. Rep. 426, 1-45. doi: 10.1016/j.physrep.2005.12.001

Mitchell, A., Romano, G. H., Groisman, B., Yona, A., Dekel, E., Kupiec, M., et al. (2009). Adaptive prediction of environmental changes by microorganisms. Nature 460, 220-224. doi: 10.1038/nature08112

Moran, M. A. (2015). The global ocean microbiome. Science 350:aac8455. doi: $10.1126 /$ science.aac8455

Morrison, P. (1964). A thermodynamic characterization of self-reproduction. Rev. Mod. Phys. 36, 517-524. doi: 10.1103/RevModPhys.36.517

Murphy, J., and Riley, J. P. (1962). A modified single solution method for the determination of phosphate in natural waters. Anal. Chim. Acta 27, 31-36. doi: 10.1016/S0003-2670(00)88444-5

Needham, D. M., and Fuhrman, J. A. (2016). Pronounced daily succession of phytoplankton, archaea and bacteria following a spring bloom. Nat. Microbiol. 1:16005. doi: 10.1038/nmicrobiol.2016.5

Odum, E. P. (1969). The strategy of ecosystem development. Science 164, 262-270.

Ottesen, E. A., Young, C. R., Gifford, S. M., Eppley, J. M., Marin, R., Schuster, S. C., et al. (2014). Multispecies diel transcriptional oscillations in open ocean heterotrophic bacterial assemblages. Science 345, 207-212. doi: $10.1126 /$ science. 1252476

Pasternak, Z., Ben Sasson, T., Cohen, Y., Segev, E., and Jurkevitch, E. (2015). A new comparative-genomics approach for defining phenotype-specific indicators reveals specific genetic markers in predatory bacteria. PLOS ONE 10:e 0142933. doi: 10.1371/journal.pone.0142933

Pianka, E. R. (1970). R-Selection and K-Selection. Am. Nat. 104, 592-597. doi: $10.1086 / 282697$

Ponomarova, O., and Patil, K. R. (2015). Metabolic interactions in microbial communities: untangling the Gordian knot. Curr. Opin. Microbiol. 27, 37-44. doi: 10.1016/j.mib.2015.06.014

Rakoff-Nahoum, S., Foster, K. R., and Comstock, L. E. (2016). The evolution of cooperation within the gut microbiota. Nature 533, 255-259. doi: 10.1038/nature17626

Reed, D. C., Algar, C. K., Huber, J. A., and Dick, G. J. (2014). Gene-centric approach to integrating environmental genomics and biogeochemical models. Proc. Natl. Acad. Sci. U.S.A. 111, 1879-1884. doi: 10.1073/pnas.1313713111

Reguera, G., McCarthy, K. D., Mehta, T., Nicoll, J. S., Tuominen, M. T., and Lovley, D. R. (2005). Extracellular electron transfer via microbial nanowires. Nature 435, 1098-1101. doi: 10.1038/nature03661

Riley, G. A. (1946). Factors controlling phytoplankton population on Georges Bank. J. Mar. Res. 6, 54-73. 
Sathyendranath, S., Stuart, V., Nair, A., Oka, K., Nakane, T., Bouman, H., et al. (2009). Carbon-to-chlorophyll ratio and growth rate of phytoplankton in the sea. Mar. Ecol. Prog. Ser. 383, 73-84. doi: 10.3354/meps07998

Schartau, M., Wallhead, P., Hemmings, J., Löptien, U., Kriest, I., Krishna, S., et al. (2017). Reviews and syntheses: parameter identification in marine planktonic ecosystem modelling. Biogeosciences 14, 1647-1701. doi: 10.5194/bg-14-1647-2017

Schauer, R., Risgaard-Petersen, N., Kjeldsen, K. U., Tataru Bjerg, J. J., B., Jørgensen, B., Schramm, A., et al. (2014). Succession of cable bacteria and electric currents in marine sediment. ISME J. 8, 1314-1322. doi: 10.1038/ismej. 2013.239

Schulz, H. N., Brinkhoff, T., Ferdelman, T. G., Mariné, M. H., Teske, A., and Jørgensen, B. B. (1999). Dense populations of a giant sulfur bacterium in Namibian shelf sediments. Science 284, 493-495. doi: $10.1126 /$ science.284.5413.493

Skene, K. (2015). Life's a gas: a thermodynamic theory of biological evolution. Entropy 17, 5522-5548. doi: 10.3390/e17085522

Skene, K. R. (2017). Thermodynamics, ecology and evolutionary biology: a bridge over troubled water or common ground? Acta Oecologica 85, 116-125. doi: 10.1016/j.actao.2017.10.010

Sogin, M. L., Morrison, H. G., Huber, J. A., Welch, D. M., Huse, S. M., Neal, P. R., et al. (2006). Microbial diversity in the deep sea and the underexplored "rare biosphere". Proc. Natl. Acad. Sci. U.S.A. 103, 12115-12120. doi: 10.1073/pnas.0605127103

Stocker, R., and Seymour, J. R. (2012). Ecology and physics of bacterial chemotaxis in the ocean. Microbiol. Mol. Biol. Rev. 76, 792-812. doi: 10.1128/MMBR.00029-12

Tilman, D. (1982). Resource Competition and Community Structure. Princeton, NJ: Princetown University Press.

Treangen, T. J., and Rocha, E. P. C. (2011). Horizontal transfer, not duplication, drives the expansion of protein families in prokaryotes. PLoS Genet. 7:e1001284. doi: 10.1371/journal.pgen.1001284

Vallino, J. J. (2000). Improving marine ecosystem models: use of data assimilation and mesocosm experiments. J. Mar. Res. 58, 117-164. doi: $10.1357 / 002224000321511223$

Vallino, J. J. (2003). Modeling microbial consortiums as distributed metabolic networks. Biol. Bull. 204, 174-179. doi: 10.2307/1543554
Vallino, J. J. (2010). Ecosystem biogeochemistry considered as a distributed metabolic network ordered by maximum entropy production. Philos. Trans. $R$. Soc. B Biol. Sci. 365, 1417-1427. doi: 10.1098/rstb.2009.0272

Vallino, J. J. (2011). Differences and implications in biogeochemistry from maximizing entropy production locally versus globally. Earth Syst. Dynam. 2, 69-85. doi: 10.5194/esd-2-69-2011

Vallino, J. J., and Algar, C. K. (2016). The thermodynamics of marine biogeochemical cycles: lotka revisited. Ann. Rev. Mar. Sci. 8, 333-3s56. doi: 10.1146/annurev-marine-010814-015843

Vallino, J. J., Algar, C. K., González, N. F., and Huber, J. A. (2014). "Use of receding horizon optimal control to solve MaxEP-based biogeochemistry problems," in Beyond the Second Law-Entropy Production and Non-Equilibrium Systems, eds R. C. Dewar, C. H. Lineweaver, R. K. Niven, and K. Regenauer-Lieb (Berlin; Heidelberg: Springer), 337-359.

Ward, B. A., Friedrichs, M. A. M., Anderson, T. R., and Oschlies, A. (2010). Parameter optimisation techniques and the problem of underdetermination in marine biogeochemical models. J. Mar. Syst. 81, 34-43. doi: 10.1016/j.jmarsys.2009.12.005

Whiteley, M., Diggle, S. P., and Greenberg, E. P. (2017). Progress in and promise of bacterial quorum sensing research. Nature 551:313. doi: 10.1038/nature24624

Wolf, D. M., and Arkin, A. P. (2003). Motifs, modules and games in bacteria. Curr. Opin. Microbiol. 6, 125-134. doi: 10.1016/S1369-5274(03)00033-X

Worden, A. Z., Follows, M. J., Giovannoni, S. J., Wilken, S., Zimmerman, A. E., and Keeling, P. J. (2015). Rethinking the marine carbon cycle: factoring in the multifarious lifestyles of microbes. Science 347:1257594. doi: 10.1126/science. 1257594

Conflict of Interest Statement: The authors declare that the research was conducted in the absence of any commercial or financial relationships that could be construed as a potential conflict of interest.

Copyright (๑) 2018 Vallino and Huber. This is an open-access article distributed under the terms of the Creative Commons Attribution License (CC BY). The use, distribution or reproduction in other forums is permitted, provided the original author(s) and the copyright owner(s) are credited and that the original publication in this journal is cited, in accordance with accepted academic practice. No use, distribution or reproduction is permitted which does not comply with these terms. 